\title{
Cholinergic Neuromuscular Synapses in Aplysia Have Low Endogenous Acetylcholinesterase Activity and a High-Affinity Uptake System for Acetylcholine
}

\author{
Philip E. Lloyd and Paul J. Church \\ Department of Pharmacological and Physiological Sciences and Committee on Neurobiology, University of Chicago, \\ Chicago, Illinois 60637
}

In the present study, we have demonstrated that $\mathrm{ACh}$ is the predominant fast excitatory transmitter used by identified motor neurons innervating feeding muscles in Aplysla. A detailed study of ACh metabolism was then carried out in a well-characterized neuromuscular preparation, intrinsic muscle 5 (15). This neuromuscular system has a high-affinity uptake system for choline. The rate of uptake of choline was increased by motor neuron stimulation, and this increased uptake appears to be selectively targeted to motor neuron terminals. These properties appear similar to those observed in vertebrate neuromuscular preparations. However, we have made two observations that are surprising in light of our knowledge concerning the vertebrate neuromuscular junction where released $\mathrm{ACh}$ is rapidly hydrolyzed by acetylcholinesterase (AChE) to choline, which is then taken up by a high-affinity uptake system. This Aplysia neuromuscular system has limited endogenous AChE activity and contains a separate high-affinity uptake system for ACh itself that actually has a higher velocity than that for choline uptake. It is possible that the uptake system for $\mathrm{ACh}$ is involved in terminating the action of released transmitter in a manner similar to that previously described for noncholinergic transmitters. Using this preparation, we have demonstrated release of labeled $\mathrm{ACh}$ in response to intracellular stimulation of identified motor neurons. The release per spike appears to be highly plastic, increasing markedly with stimulation frequency. This preparation is amenable to study the regulation of release of peptide and conventional transmitters from the terminals of individual neurons.

[Key words: cholinergic synapse, AChE, ChAT, ACh uptake, cotransmitters, neuromuscular]

Acetylcholine (ACh) is the fast excitatory transmitter used at some neuromuscular synapses in mollusks. The release of peptide cotransmitters from select cholinergic neuromuscular synapses have been studied extensively in Aplysia, but little atten-

Received Dec. 30, 1993; revised Apr. 13, 1994; accepted Apr. 28, 1994

Wc thank L. E. Fox, G. A. Phares, and M. D. Whim for critical reading of the manuscript. We are particularly grateful to J. $H$. Schwartz for his thoughtful criticism of an earlier version of the manuscript. This work was supported by NRSA 1-F31-MH10240 to P.J.C. and BNS-9121146 to P.E.L.

Correspondence should be addressed to Philip E. Lloyd, Department of Pharmacological Sciences, University of Chicago, 947 East 58th Street, Chicago, IL 60637.

Copyright (c) 1994 Society for Neuroscience $0270-6474 / 94 / 146722-12 \$ 05.00 / 0$ tion has been given to $\mathrm{ACh}$ synthesis, release, and inactivation at the same synapses. We set out to investigate these phenomena in a preparation consisting of neuromuscular synapses between two identified cholinergic motor neurons (B15 and B16; Cohen et al., 1978) and the muscle fibers of intrinsic muscle 5 (I5; Howells, 1942; also called the ARC muscle). B15 and B16 are members of the ventral cluster of motor neurons (MNs) that innervate buccal muscles involved in generating biting and swallowing movements. In addition to $\mathrm{ACh}$, both $\mathrm{MNs}$ also contain several modulatory neuropeptide transmitters. B15 contains the small cardioactive peptides (SCPs) and the buccalins, while B16 contains the buccalins and the myomodulins (Cropper et al., 1987a,b, 1988, 1990b; Church and Lloyd, 1991). At the ultrastructural level, SCP-like immunoreactivity is located in densecore vesicles in varicosities in this muscle (Cropper et al., 1987a). These same varicosities also contain smaller electron-luscent vesicles similar to cholinergic vesicles described in other animals. Recently, the release of the SCPs from the terminals of B15 in I5 muscle was demonstrated (Whim and Lloyd, 1989, 1990; Cropper et al., 1990a). This release is sharply dependent on the stimulation parameters with significant relcasc of the SCPs only occurring with stimulation at a relatively high frequency for bursts of long duration. Since B 15 can produce cholinergically mediated contractions with stimulation parameters that do not cause measurable release of the SCPs, it appears that B 5 can function in two states: as a predominantly cholinergic neuron, or as a combined cholinergic/peptidergic neuron (Whim et al., 1993). The determination of the factors that regulate the metabolism of multiple transmitters released from individual neurons is vital to our understanding of neuronal function (Bartfai et al., 1988; Kupfermann, 1991).

In the present study, we have set out to determine how commonly ACh is used as the fast excitatory transmitter in ventral cluster MNs. We then concentrated our study of $\mathrm{ACh}$ metabolism on the I5 neuromuscular preparation. We have made two observations that are surprising in light of our knowledge concerning the vertebrate neuromuscular junction where releascd $\mathrm{ACh}$ is rapidly hydrolyzed by acetylcholinesterase (AChE) to choline, which is then taken up. First, these Aplysia neuromuscular synapses have very limited endogenous $\mathrm{AChE}$ activity. Second, this preparation contains a separate high-affinity uptake system for $\mathrm{ACh}$ itself that actually has a higher velocity than the high-affinity uptake system for choline. It is possible that the uptake system for $\mathrm{ACh}$ is involved in terminating the action of released transmitter in a manner similar to that described for biogenic amines and amino acid transmitters at other synapses (Amara and Kuhar, 1993). 


\section{Materials and Methods}

Animals. Aplysia californica (70-220 gm) were obtained from Marinus Inc. (Long Beach, CA), maintained in circulating artificial sea water (ASW) at $16^{\circ} \mathrm{C}$, and fed dried seaweed every $3 \mathrm{~d}$. All experiments were carried out at $21-23^{\circ} \mathrm{C}$, as were previous studies on peptide cotransmitter release in the same preparation (Whim and Lloyd, 1989, 1990).

Intracellular injection of ${ }^{3} \mathrm{H}$-choline and synthesis of labeled $\mathrm{ACh}$. Individual MNs were identified as described previously (Church and Lloyd, 1991; Church et al., 1993) using a series of criteria that included size and position within the buccal ganglion, synaptic connections from identified interneurons, axonal projections, and the identity of the muscles they innervate. Electrodes were tip filled with a solution of $1 \mathrm{M} \mathrm{KCl}$, $0.5 \%$ fast green, and ${ }^{3} \mathrm{H}$-choline $(\sim 70 \mathrm{Ci} / \mathrm{mmol}$; Amersham $)$ concentrated to $200 \mathrm{mCi} / \mathrm{ml}$. These electrodes were acceptable for voltage recording and were used to pressure inject the solution. Since the final concentration of choline in the electrode was low $(3 \mu \mathrm{M})$, the injections were small ( $<1 \%$ of cell volume), and normal concentrations of choline in Aplysia neurons are over $100 \mu \mathrm{M}$ (McCaman et al., 1973), the injections would have little effect on intracellular choline levels. Filling was monitored visually by the change in cell color. After injection, the ganglion was incubated for $1 \mathrm{hr}$ in normal (n) ASW containing $10 \mu \mathrm{M}$ unlabeled choline to inhibit uptake of any leaked labeled choline. Neuronal cell bodies were dissected manually using freeze substitution (Ono and McCaman, 1980) and extracted into a tube containing $50 \mu \mathrm{l}$ of $85 \%$ ethanol, $15 \% 1 \mathrm{M}$ acetic acid, and $300 \mathrm{nmol}$ each of unlabeled choline and ACh. This tube was kept on dry ice, and then stored at $-20^{\circ} \mathrm{C}$. Samples were dried and analyzed by HPLC to determine the fate of the injected labeled choline (see below).

Uptake of ${ }^{3} \mathrm{H}$-choline and ${ }^{3} \mathrm{H}-\mathrm{AC}$ Ch into 15 neuromuscular preparations. Animals were immobilized with an injection of isotonic $\mathrm{MgCl}_{2}$. All dissections were carried out in high- $\mathrm{Mg}^{2+}(110 \mathrm{~mm})$, low-Ca ${ }^{2+}(0.5 \mathrm{~mm})$ ASW. Paired I5 muscles were cut from the remainder of the buccal mass and cut in half longitudinally to produce four muscle sections. These were washed extensively with nASW for at lcast $3 \mathrm{hr}$ to wash as much blood (which contains both choline and cholinesterate activity) as possible from the muscle. Constant agitation was used to ensure mixing during all washes and incubations described here and below. Muscle sections were incubated in 10-50 $\mathrm{nM}{ }^{3} \mathrm{H}$-choline or ${ }^{3} \mathrm{H}$-ACh. In some cases, additional unlabeled choline or ACh was added to yield the correct total concentration. In most cases, bath volumes were $\sim 1000$ fold larger than muscle volumes to prevent significant depletion and to ensure that there was limited hydrolysis of ACh (see below). At the end of the incubation periods (3-100 min), muscle segments were washed for 15 min each in two consecutive baths containing high- $\mathrm{Mg}^{2+} /$ low$\mathrm{Ca}^{2+}$ ASW with no added choline or ACh. One limitation of these experiments is that in resting muscles at very low bath concentrations of choline, it is likely that the efflux of endogenous choline from the muscles would increase the local concentration of cholinc above that in the bath. This may also be a problem with ACh when the neuromuscular preparation is stimulated. Because of these limitations and the complexity of uptake systems in this preparation, we have only described the separate uptake systems in a qualitative fashion.

Dissection of the 15 neuromuscular system. These were carried out in a fashion similar to those already described (Whim and Lloyd, 1989). In brief, the buccal mass/buccal ganglia complex was removed from the animal and cut in half. In experiments involving intracellular stimulation of $\mathrm{B} 15$ or B16, the hemiganglion containing the cell bodies of these MNs was left attached to the muscle via buccal nerve 3 (N3), which contains their motor axons. A third MN, termed B11, is also cholinergic and has its axon in N3 but it produces very small EJPs in the I5 muscle fibers and primarily innervates another muscle (Jordan et al., 1993). All other nerves and connectives were severed. In experiments using extracellular suction electrodes, N3 was cut near its connection to the hemiganglion. In all experiments, the muscle that provides a base for I5 was trimmed as much as possible without damaging N3 (see Fig. 1; Weiss et al., 1978). After dissection, all preparations were washed extensively with nASW for at least $3 \mathrm{hr}$ to wash as much blood as possible from the muscles.

Loading I5 neuromuscular preparations with ${ }^{3} H$-choline. N3 stimulation increased ${ }^{3} \mathrm{H}$-choline uptake and synthesis of labeled $\mathrm{ACh}$ (see Results). In most experiments, stimulation was used to "load" the preparation with labeled ACh probably primarily in the presynaptic terminals (see Results). In experiments with N3 cut, a suction electrode was used to stimulate N3 (4 sec $25 \mathrm{~Hz}$ bursts with $6 \mathrm{sec}$ intervals for

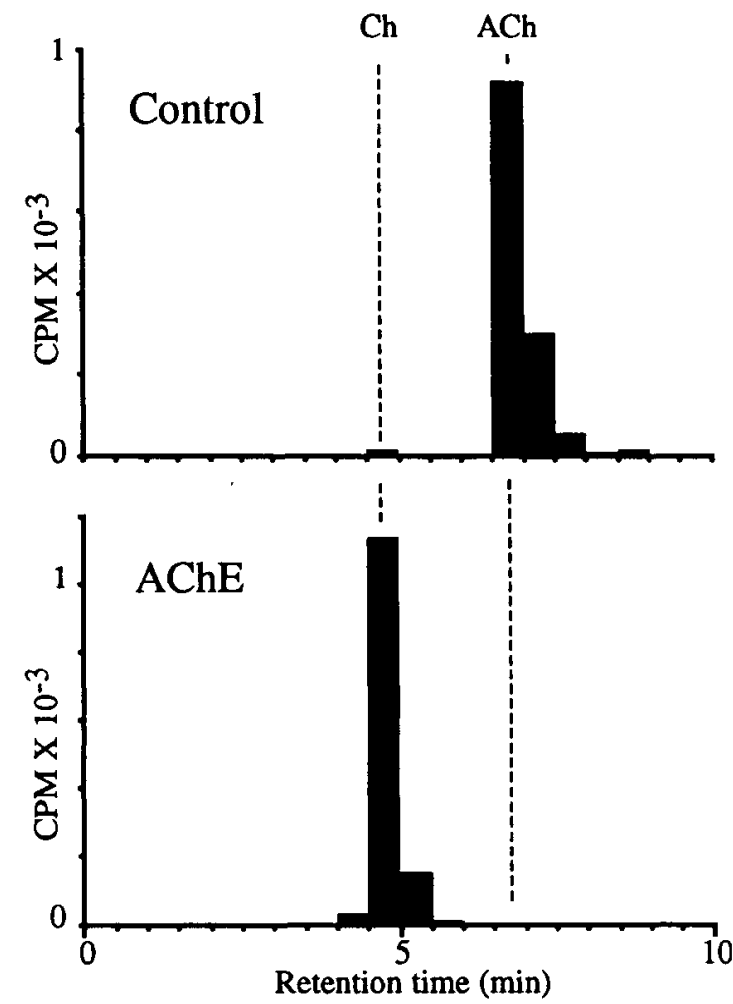

Figure 1. HPLC profiles of ACh peak incubated in buffer ( $\mathrm{pH} 7.8$ ) for 60 min (Control) or with AChE in the same buffer $(A C h E)$. The ACh peak was obtained by HPLC of a buccal ganglion incubated in ${ }^{3} \mathrm{H}-$ choline for $30 \mathrm{~min}$, which is sufficient period for the ganglion to take up the choline and synthesize labeled ACh. The ganglion was then extracted and run with the same gradient shown here to obtain the labeled ACh peak used in these incubations. Note that AChE hydrolyzed all of the label in the ACh peak to a substance with the same retention time as choline $(C h)$. Dashed lines indicate retention times of unlabeled choline and $\mathrm{ACh}$ added to the samples and monitored by absorbance at $206 \mathrm{~nm}$. Essentially the same results were obtained for the ACh peak purified from 15 muscle, or with the ACh peaks from either buccal ganglion or muscle incubated for 60 min under basic conditions $\mathrm{pH}$ 10).

$30 \mathrm{~min})$ during incubation in ${ }^{3} \mathrm{H}$-choline ( $\sim 70 \mathrm{Ci} / \mathrm{mmol}$; Amersham). When N3 remained connected to the buccal ganglion, the nerve was stimulated by placing it through a petroleum jelly gap (Lloyd, 1988) and passing brief $(1.5 \mathrm{msec})$ current pulses across the gap with silver chloride electrodes. This procedure was used because long term en passant stimulation with a suction electrode occasionally damages axons.

Collection of labeled substances released from loaded Is neuromuscular preparations. The 15 muscle was positioned with a retractable hook into a collection apparatus with a bath volume of $30 \mu \mathrm{l}$ and was perfused via a peristaltic pump at a flow rate of $333 \mu \mathrm{l} / \mathrm{min}$ (one bath volume $/ 5 \mathrm{sec}$ ). The base muscle provided an effective seal for the collection apparatus (Church et al., 1993). Outflow was collected into vials, scintillation fluid added, and the samples counted without further extraction. Collection periods of $3 \mathrm{~min}$ (volume, $1 \mathrm{ml}$ ) were used throughout. Counting efficiency including quenching by the ASW was $\sim 50 \%$. In some experiments, the scintillation vials were spiked with $100 \mu \mathrm{l}$ of $110 \mathrm{~mm}$ heptafluorobutyric acid (HFBA), $10 \mathrm{~mm}$ triethylamine (TEA) containing $300 \mathrm{nmol}$ each of unlabeled choline and ACh. Portions of these collected samples were analyzed by HPLC (see below). The collection apparatus was also used as an extracellular electrode to ensure that EJPs followed intracellular somatic spikes one for one. Silver chloride electrodes were placed inside and just outside the apparatus, which was pressed firmly onto the base muscle. Electrodes were attached to a Grass P15 A.C. amplifier. The inflow reservoir was shielded to reduce noise.

Determination of cholinesterase activity. I5 muscles were dissected away from the base muscle and cut longitudinally into two segments. 

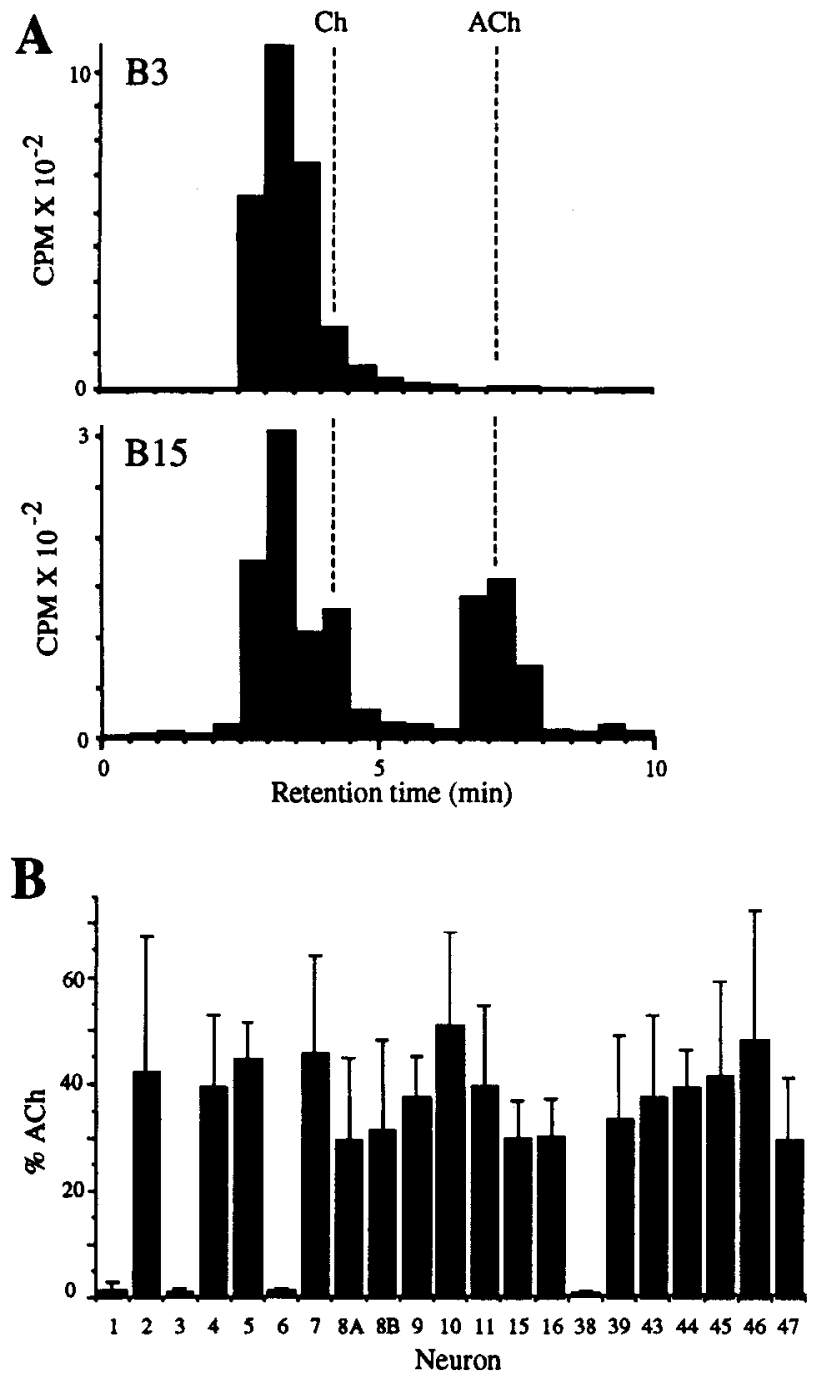

Figure 2. $A$, HPLC profiles of extracts from single identified neuronal somata injected with ${ }^{3} \mathrm{H}$-choline. Neurons were dissected and extracted $\sim 1 \mathrm{hr}$ after injection. $B 3$ profile is typical of neurons that synthesized very low levels of labeled $\mathrm{ACh}(<1.5 \%)$. BI5 profile is typical of neurons that synthesized high levels of labeled ACh ( $>30 \%$ ). Additional pharmacological data indicate that B15 is cholinergic while B3 is not. Dashed lines indicate retention times of unlabeled $\mathrm{Ch}$ and $\mathrm{ACh}$ added to cell cxtracts and monitored by absorbance at $206 \mathrm{~nm}$. Total recovered counts reflects the fact that $\mathrm{B} 3$ is a larger neuron than $\mathrm{B} 15$. The identities of the labeled material with retention times between 3 and 4 min has not been determined (see text). $B$, Summary of the results from ${ }^{3} \mathrm{H}-\mathrm{Ch}$ injections into identified neuronal somata in the buccal ganglion. Neurons 1 and 2 regulate contractile activity of the gut (Lloyd et al., 1988) while all the other neurons make excitatory or inhibitory neuromuscular synapses on buccal muscle. Identifying characteristics of neurons up to 45 have been described previously (Church and Lloyd, 1991). MN B46 is located adjacent to B2 and provides excitatory innervation to muscle I1 via nerve 2. B47 is an inhibitory MN described elsewhere (Church et al., 1993). \%ACh, percentage of total recovered label that coeluted with unlabeled $\mathrm{ACh}$. Values are mean $\pm \mathrm{SD}(n \geq 4)$.

These were then washed for $\sim 3 \mathrm{hr}$ in eight changes of nASW to wash as much blood as possible from the muscle segments. Cholinesterase activities were measured by incubating muscle segments (segments weighing $1-4 \mathrm{mg}$ were incubated at a ratio of $1 \mathrm{mg}$ wet weight $/ 10 \mu \mathrm{l}$ $\mathrm{nASW}$ ) or freshly collected blood ( $1 \mu \mathrm{l} \mathrm{blood} / 10 \mu \mathrm{l}$ ASW) with $10 \mu \mathrm{M}$ ${ }^{3} \mathrm{H}$ ACh. At intervals, the bath and muscle segment were extracted and analyzed by HPLC (see below). In most cases, parallel experiments were carried out with $100 \mu \mathrm{M}$ eserine sulphate (Sigma) added to the nASW.

Intracellular stimulation of B15 or B16. The ganglion and base mus- cles were continuously superfused with high- $\mathrm{Mg}^{2+} / 10 w-\mathrm{Ca}^{2+} \mathrm{ASW}$ to suppress synaptic transmission. Motor neurons were impaled with two electrodes $(R \sim 10 \mathrm{M} \Omega)$, one to pass current and the other to monitor voltage. Intracellular spikes were individually generated by $10 \mathrm{msec}$ depolarizing current pulses. B16 was often spontaneously active so in experiments involving B15, B16 was impaled and mechanically lesioned before the start of the experiment. Lesions of the cell body produced a brief volley of high-frequency EJPs in $I 5$ muscle and then no further EJPs that were not evoked by B15 stimulation were observed. In experiments involving $\mathrm{B} 16$, the cell was hyperpolarized tonically between stimulation periods. B 15 was never spontaneously active under these experimental conditions.

Analysis of labeled substances by HPLC. Labeled ACh could be separated completely from labeled choline and other labeled substances by reverse phase HPLC on an Isco $5 \times 250 \mathrm{~mm} \mathrm{C8}(5 \mu \mathrm{m})$ column with a gradient from $8 \%$ to $20 \% \mathrm{CH}_{3} \mathrm{CN}$ in $7 \mathrm{~min}$, and then held at $20 \%$ for 2 min before reequilibration. Both $\mathrm{H}_{2} \mathrm{O}$ and $\mathrm{CH}_{3} \mathrm{CN}$ solutions contained $11 \mathrm{~mm}$ HFBA and $1 \mathrm{~mm}$ TEA. All HPLC injections contained 100$300 \mathrm{nmol}$ each of unlabeled choline and ACh. The elution of these compounds was monitored at $206 \mathrm{~nm}$. Fractions $(0.5 \mathrm{~min})$ were collected and counted after the addition of scintillation fluid. Labeled ACh peaks were prepared by incubating either buccal ganglia or I5 muscle (with stimulation of $\mathrm{N} 3$ ) in $50 \mathrm{nM}^{3} \mathrm{H}$-choline. Extracts from the ganglia or muscle were run on HPLC to purify the ACh peaks. The nature of the label in these peaks was analyzed using three procedures: (1) incu-

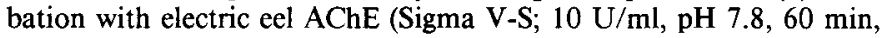
$22^{\circ} \mathrm{C}$ ) followed by HPLC (Fig. 1); (2) incubation under basic conditions ( $5 \mathrm{~mm} \mathrm{NaOH}, \mathrm{pH} 10,60 \mathrm{~min}, 22^{\circ} \mathrm{C}$ ) followed by HPLC; (3) a second mode of HPLC using $20 \mathrm{~mm}$ TEA acetate, $0.1 \mathrm{~mm}$ Na octyl sulfate (pH 5 ) as the mobile phase with the same column. Incubation with AChE or $\mathrm{NaOH}$ resulted in complete hydrolysis $(>99 \%)$ of the labeled $\mathrm{ACh}$ peak from either ganglia or muscle to a labeled substance that has the same retention time as choline (e.g., Fig. 1). In addition, the label in the ACh peaks continued to coelute with ${ }^{3} \mathrm{H}-\mathrm{ACh}$ run in parallel on the second mode of HPLC. Using these three criteria, we conclude that essentially all of the label in the ACh peak is labeled ACh.

\section{Results}

\section{Identified motor neurons in buccal ganglia are predominantly cholinergic}

The first question we wished to answer is how commonly ACh is used as the fast excitatory transmitter at neuromuscular synapses in buccal muscle. It has been shown that a powerful criterion to determine if an Aplysia neuron is cholinergic is to measure the synthesis of $\mathrm{ACh}$ from injected labeled choline (Eisenstadt et al., 1973; Cohen et al., 1978). Apparently, cholinergic somata in Aplysia contain significant choline acetyltransferase (ChAT) activity while noncholinergic neurons contain very little ChAT activity (Giller and Schwartz, 1971a). Individual MNs were identified using a battery of criteria (Church and Lloyd, 1991; Church et al., 1993) and a solution containing ${ }^{3} \mathrm{H}$-choline was pressure injected into each somata. After incubation, individual somata were dissected, processed, and analyzed by HPLC to separate labeled choline, $\mathrm{ACh}$, and other substances. Figure 2 shows examples of the labeling patterns of neurons B15 and B3. B15 is cholinergic by the criteria that it contains significant ChAT activity and that its EJPs are blocked by hexamethonium (Cohen et al., 1978) and B3 is noncholinergic by the criteria that it contains essentially no ChAT activity (Fig. 2) and its EJPs are not blocked by hexamethonium (Lotshaw and Lloyd, 1990). Using our extraction procedures and HPLC, we observed a major peak of label with short retention time that apparently was not observed in previous studies using paper electrophoresis to separate labeled substances from Aplysia neurons. This substance(s) appears to be a major product in both cholinergic and noncholinergic neuronal extracts. Labeled substance(s) with similar retention times were also observed in muscles which took up ${ }^{3} \mathrm{H}$-choline from the 
bath (e.g., Figs. 9, 12) or crude muscle extracts incubated with ${ }^{3} \mathrm{H}$-choline. However, boiling of the extracts before incubation with ${ }^{3} \mathrm{H}$-choline prevented the appearance of this substance(s), suggesting that its production was enzymatic. Several common choline metabolites do have similar retention times with this peak. These include betaine and cytidine diphosphocholine, but not phosphorylcholine, which has a retention time between those of choline and ACh. Since this substance(s) does not appear to be involved in cholinergic transmitter function (see below) and was only slightly retained by the column, its identity has not been further pursued.

Figure $2 B$ summarizes the results from ${ }^{3} \mathrm{H}$-choline injections into identified MNs. ChAT activity of individual neurons fell into two categories. In one category, labeled ACh represents $30 \%$ or more of the recovered label (mean of all cells in this category, $37.8 \pm 6.9 \%$, \pm SEM). Note that the ChAT activities of previously identified cholinergic neurons fall into this group (B4, B5, B1 5, B16, B47; Gardner and Kandel, 1977; Cohen et al., 1978; Church et al., 1993). In the other category, labeled ACh was less than $1.5 \%$ of recovered label (mean of all cells in this category, $0.8 \pm 0.3 \%$ ). Of these neurons, additional pharmacological evidence confirmed that B3 and B38 are not cholinergic (Lotshaw and Lloyd, 1990; Church et al., 1993). These results suggest that 17 of 21 identified MNs are cholinergic. One of these cholinergic neurons is inhibitory (B47) and two are inhibitory/excitatory (B4 and B5). The four noncholinergic neurons are excitatory, and there is evidence that thcir conventional transmitter may be an excitatory amino acid, most likely glutamate (Fox and Lloyd, 1993). Thus, the most prevalent fast excitatory transmitter used by buccal MNs is ACh.

\section{Separate uptake systems for ACh and choline are present in I5 neuromuscular preparations}

We concentrated our investigations of choline and ACh metabolism on the I5 neuromuscular system since this preparation has been extensively studied. It is important to emphasize that in all cases the preparations were washed extensively with nASW for several hours to wash away as much blood as possible. This step was necessary because the blood contains significant amounts of choline $(\sim 10 \mu \mathrm{M}$; Schwartz et al., 1975) and AChE activity (Giller and Schwartz, 1971b; Bevelaqua et al., 1975; also see below). I5 muscle preparations consist primarily of muscle fibers with a small proportion of the muscle volume being the axons and terminals of B15 and B16 (Cohen et al., 1978).

To study the metabolism of choline and $\mathrm{ACh}$, we first investigated the ability of I5 neuromuscular preparations to hydrolyze labeled ACh. In contrast to vertebrate neuromuscular junctions (Potter, 1970), I5 neuromuscular preparations contain little cholinesterase activity (see below). In the absence of blood, there is measurable but limited hydrolysis of ACh. Because measurements of $\mathrm{AChE}$ activity are complicated by the uptake of unhydrolyzed $\mathrm{ACh}$, they will be described after the uptake experiments.

When incubated with low concentrations ( $50 \mathrm{nM}$ ) of labeled choline or ACh, I5 muscle segments actively concentrated both substances linearly with respect to time (Fig. 3). The velocity of ACh uptake was approximately fourfold greater than choline uptake. These are active processes. For example, after incubation for $100 \mathrm{~min}$, labeled $\mathrm{ACh}$ was concentrated 45 -fold over bath levels and choline was concentrated 10-fold. Uptake at early time points indicates little lag at the beginning of the incubations suggesting that the labeled substances diffused rap-

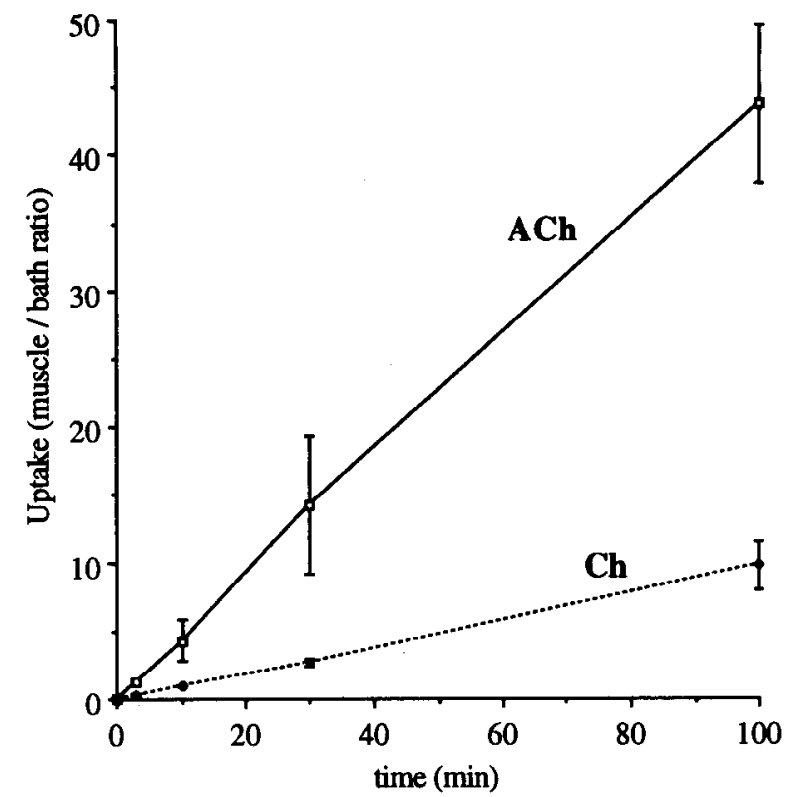

Figure 3. Uptake of ${ }^{3} \mathrm{H}-\mathrm{ACh}$ or ${ }^{3} \mathrm{H}-\mathrm{Ch}$ by resting (unstimulated) $\mathrm{I5}$ muscles. Muscle segments were incubated with $50 \mathrm{~nm} \mathrm{ACh}$ or $\mathrm{Ch}$ for the indicated times. ACh is taken up at a rate approximately fourfold higher than $\mathrm{Ch}$ and both are taken up at a linear rate for at least 100 $\mathrm{min}$. Muscle : bath ratio was calculated as (cpm/ $\mathrm{mg}$ wet weight muscle) $\div(\mathrm{cpm} / \mu \mathrm{l}$ bath). This leads to a moderate underestimate of uptake as some of the muscle is extracellular space. Values are mean $\pm \mathrm{SD}(n=$ 3).

idly to the uptake sites. In these experiments and those described below, we added no AChE inhibitors, but bath volumes were about 1000-fold greater than muscle volumes so that only a small portion of ACh was hydrolyzed (AChE activity was determined with bath volumes only 10 -fold greater than muscle). This large volume ratio also prevented the uptake from significantly depleting bath levels of $\mathrm{ACh}$ or choline. The finding that the uptake of $\mathrm{ACh}$ had a considerably higher velocity than that of choline suggests that the uptake of choline hydrolyzed from ACh must be a very small component of the observed ACh uptake. In addition, HPLC of muscle segments incubated in labeled $\mathrm{ACh}$ indicated that most of the total label remained as $\mathrm{ACh}(67 \pm 5 \%, \pm \mathrm{SD}, n=12)$.

The ratio of ACh uptake to choline uptake was dependent on concentration (Fig. 4). ACh was taken up at a rate approximately fourfold higher than choline up to concentrations of $\sim 10 \mu \mathrm{M}$. At higher concentrations, this ratio declined and ACh and choline were taken up at the same rate at $330 \mu \mathrm{M}$ and above. A possible explanation for these results is that there are two uptake systems, one that functions at high concentrations, has a high capacity, and does not distinguish between choline and $\mathrm{ACh}$, and a second process that has a higher affinity than the first process and is selective for $\mathrm{ACh}$. The concentration dependence of the uptake of labeled choline and ACh were also determined (Fig. 5A). The curves do not saturate and indeed the curve for choline is nearly linear as was also observed for choline uptake into the Aplysia CNS (Schwartz et al., 1975). If the explanation given above is correct, then subtracting uptake of choline from the uptake of $\mathrm{ACh}$ should produce a saturating curve that would represent the high-affinity uptake selective for $\mathrm{ACh}$. Such a curve is indeed generated and indicates that the high-affinity uptake of ACh appears to have a $K_{\mathrm{m}}$ between 5 and $10 \mu \mathrm{M}$ (Fig. $5 B$ ).

Additional support for the explanation given above comes 


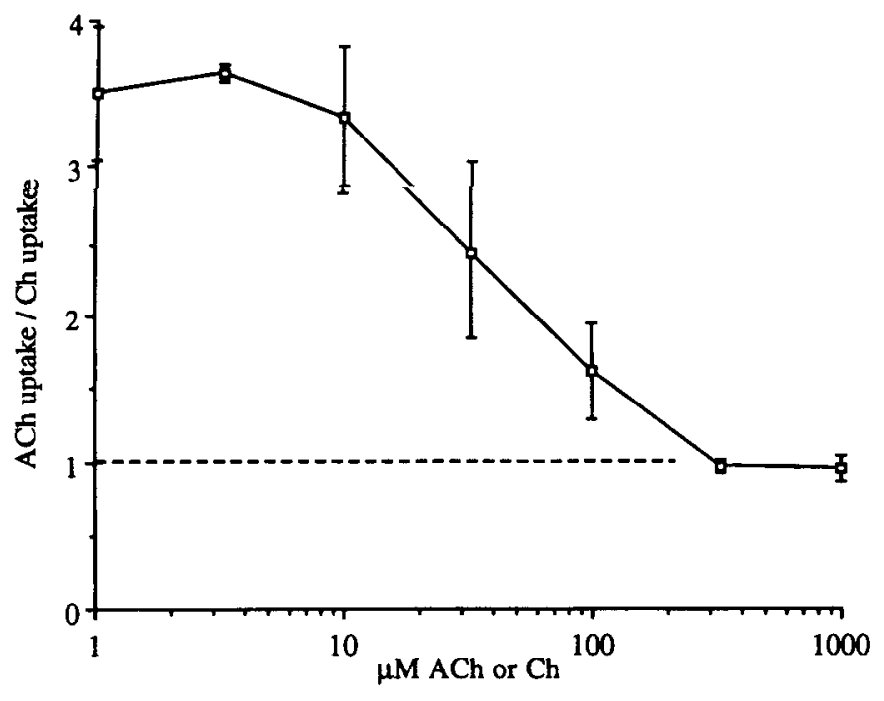

Figure 4. The ratio of $\mathrm{ACh}: \mathrm{Ch}$ uptake into $\mathrm{I} 5$ muscle segments decreased at higher concentrations. Unlabeled $\mathrm{ACh}$ or $\mathrm{Ch}$ were added to $10 \mathrm{nM}{ }^{3} \mathrm{H}$-ACh or ${ }^{3} \mathrm{H}-\mathrm{Ch}$ to produce the indicated concentrations. Incubation periods were $30 \mathrm{~min}$. Muscle segments were paired so that one segment from an animal was incubated with a particular concentration of ACh while the a second segment from the same animal was incubated with the same concentration of $\mathrm{Ch}$. Values are mean $\pm \mathrm{SD}$ $(n=3)$.

from experiments using choline or $\mathrm{ACh}$ in competition experiments. High concentrations ( $1 \mathrm{mM}$ ) of choline or ACh equally reduced uptake of labeled choline, but $\mathrm{ACh}$ was much more effective than choline at reducing ACh uptake (Fig. 6). One explanation for these results is that unlabeled ACh competes effectively with the high affinity uptake selective for ACh as well as with the lower-affinity/high-capacity system that takes up both ACh and choline. By contrast, unlabeled choline only competes effectively with the lower affinity system that takes up both $\mathrm{ACh}$ and choline. Hemicholinium-3 (HC-3) has been used extensively as an inhibitor of choline uptake at vertebrate cholinergic synapses (e.g., Potter, 1970). However, in 15 neuromuscular preparations, $\mathrm{HC}-3(1 \mathrm{~mm})$ was less effective than choline itself at blocking choline uptake, and less effective than $\mathrm{ACh}$ itself at blocking ACh uptake. Taken together with results from central ganglia (Schwartz et al., 1975), it appears that HC-3 is not an effective inhibitor of choline or ACh uptake in Aplysia.

Many high-affinity uptake systems are dependent on external $\mathrm{Na}^{+}$concentrations (Amara and Kuhar, 1993). In the 15 neuromuscular system, choline and ACh uptake showed markedly different dependencies on external Na+ ${ }^{+}$(Fig. 7). To ensure that uptake is through a high-affinity system, low concentrations (10 nM) of either choline or ACh were used. Replacing all but $5 \mathrm{~mm}$ $\mathrm{Na}^{+}$(normal $\mathrm{Na}^{+}$concentration in ASW is $460 \mathrm{mM}$ ) with $N$-methyl glucamine inhibited ACh uptake 10 -fold but reduced choline uptake less than twofold. Using Tris to replace $\mathrm{Na}^{+}$produced a larger inhibition of both choline and ACh uptake, suggesting that Tris has some other effects in addition to replacing $\mathrm{Na}^{+}$. Nevertheless, with either $N$-methyl glucamine or Tris replacing $\mathrm{Na}^{+}, \mathrm{ACh}$ uptake was inhibited approximately fivefold more effectively than choline uptake. These results provide additional evidence for the existence of a separate uptake system for ACh.

Choline uptake and metabolism have been extensively studied in central ganglia of Aplysia (Schwartz et al., 1975), but this
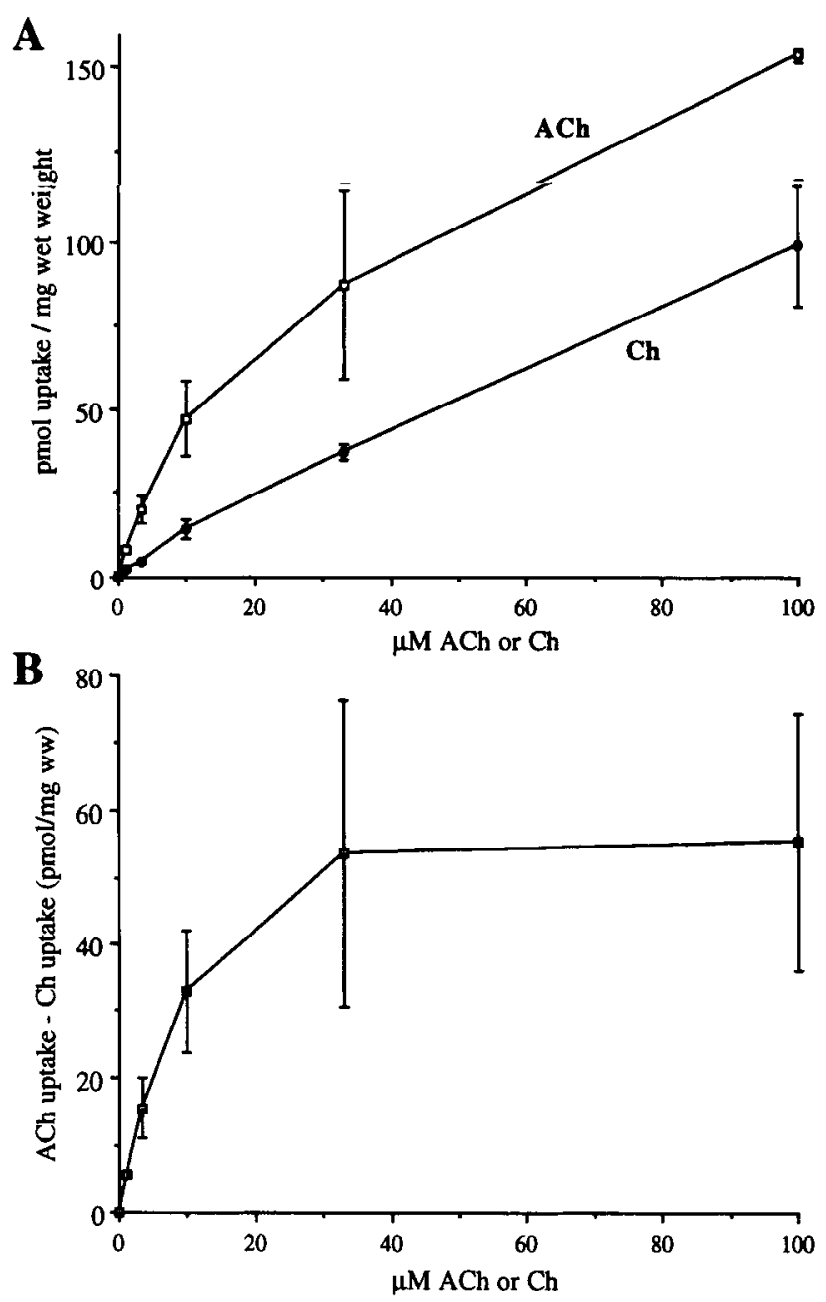

Figure 5. $A$, Concentration dependence of $\mathrm{ACh}$ and $\mathrm{Ch}$ uptake into I5 muscle segments. Unlabeled ACh or $\mathrm{Ch}$ were added to $10 \mathrm{nM}{ }^{3} \mathrm{H}$ $\mathrm{ACh}$ or ${ }^{3} \mathrm{H}$-Ch to produce the indicated concentrations. Incubation periods were $30 \mathrm{~min}$. Uptake of $\mathrm{ACh}$ and $\mathrm{Ch}$ was linear for at least 50 min at low concentrations (e.g., Fig. 3) and at the highest concentration tested ( $100 \mu \mathrm{M}$; data not shown). Muscle segments were paired so that one segment from an animal was incubated with a particular concentration of ACh while the a second segment from the same animal was incubated with the same concentration of $C h$. Values are mean $\pm S D$ $(n=3)$. B. Subtracting uptake of $\mathrm{ACh}$ from uptake of $\mathrm{Ch}$ for each pair of muscle segments incubated with the same concentrations of $\mathrm{ACh}$ and Ch yields a saturating curve. Values are mean $\pm \mathrm{SD}(n=3)$.

study did not address the possibility of ACh uptake. Accordingly, we wished to determine if a high-affinity uptake system for ACh exists in central ganglia. In these experiments, the connective tissue sheath that surrounds the ganglia and contains some muscle cells was manually trimmed away so the ganglia consisted predominantly of neuronal cell bodies and neuropil, although the connective tissue could not be removed completely (Coggeshall, 1967). Paired buccal ganglia were incubated in either $50 \mathrm{nM}{ }^{3} \mathrm{H}-\mathrm{ACh}$ or $50 \mathrm{nM}{ }^{3} \mathrm{H}$-Ch in the presence of $100 \mu \mathrm{M}$ eserine, which fully inhibits the considerable $\mathrm{AChE}$ activity found in ganglia (Schwartz et al., 1975). After incubation for $30 \mathrm{~min}$, the ganglion to bath ratio was $13.0 \pm 1.8( \pm \mathrm{SD}, n=3)$ for labeled $\mathrm{ACh}$, and $5.7 \pm 0.9$ for labeled choline. Ganglia : bath ratios were calculated as $(\mathrm{cpm} / \mathrm{mg}$ wet weight ganglion) $\div(\mathrm{cpm} /$ $\mu \mathrm{l}$ bath volume). The uptake of $\mathrm{ACh}$ was very similar to that observed in 15 muscles, while that of choline was about twice 

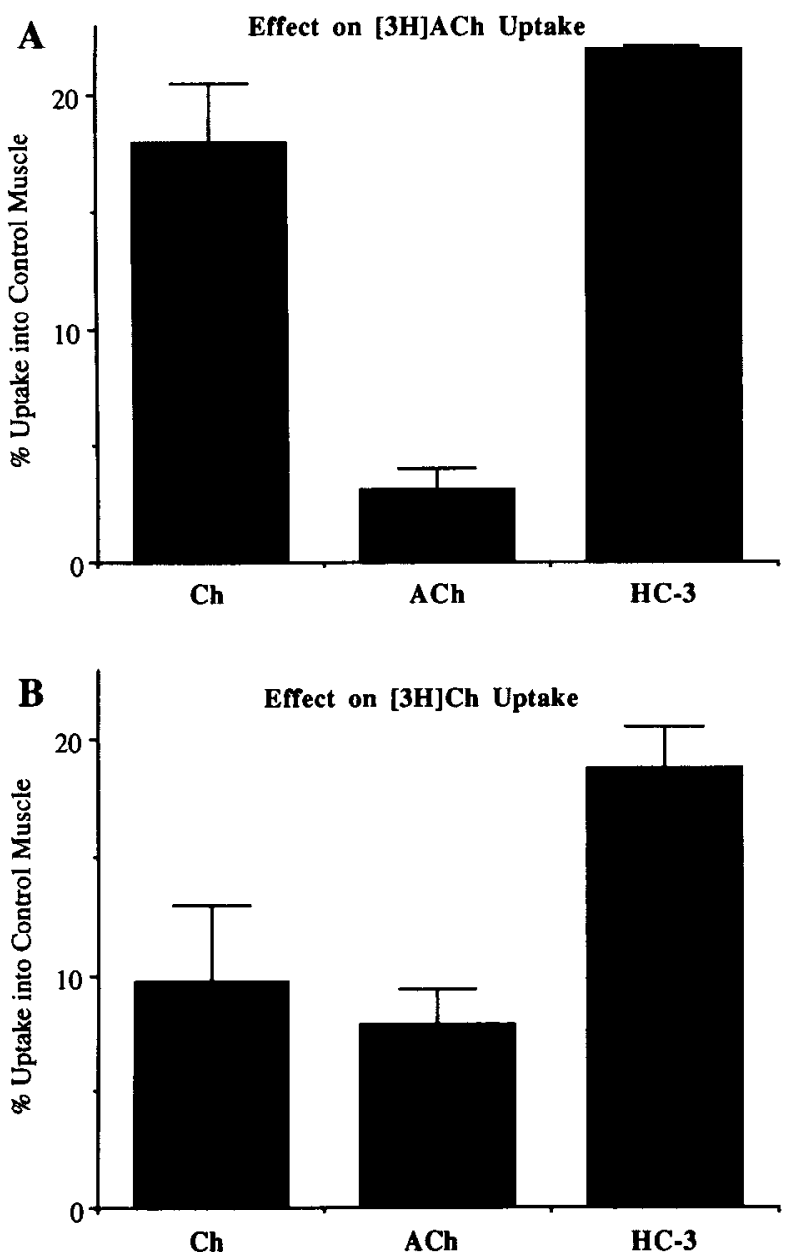

Figure 6. Inhibition of uptake of labeled $\mathrm{ACh}$ or $\mathrm{Ch}$ by high concentrations of $\mathrm{Ch}, \mathrm{ACh}$, or hemicholinium-3 (HC-3). One of a pair of I5 muscles from an animal was incubated with $10 \mathrm{nM}{ }^{3} \mathrm{H}-\mathrm{ACh}$ or ${ }^{3} \mathrm{H}-\mathrm{Ch}$, while the other muscle was incubated with the label plus $1 \mathrm{~mm}$ unlabeled $\mathrm{Ch}, \mathrm{ACh}$, or $\mathrm{HC}-3$. Incubation periods were $30 \mathrm{~min}$. Values are mean $\pm \mathrm{SD}(n=3)$.

that observed in the muscle. Finally, since abdominal ganglia were generally used for previous studies of choline uptake, the uptake of labeled $\mathrm{ACh}$ into this ganglion was also measured. In identical experiments to those described above, the ganglion to bath ratio was $10.2 \pm 1.9( \pm \mathrm{SD}, n=3)$, a value very similar to that observed for the buccal ganglia. In the case of the abdominal ganglion, the nature of the labeled substance present in the ganglion was analyzed by HPLC. Most of the label (74.8 $\pm 1.0 \%$, $\pm \mathrm{SD}, n=3$ ) was found to be $\mathrm{ACh}$ even when the 30 min wash period used to remove extracellular label was carried out in the absence of eserine. Thus, central ganglia also contain a high-affinity uptake system for $\mathrm{ACh}$, and this $\mathrm{ACh}$ is sequestered away from $\mathrm{AChE}$ activity.

\section{Stimulation increases ${ }^{3} H$-choline uptake and $A C h$ synthesis but not ${ }^{3} \mathrm{H}$-ACh uptake}

When I5 muscles were incubated for $30 \mathrm{~min}$ in $50 \mathrm{nM}{ }^{3} \mathrm{H}$ choline, $36 \pm 7 \%( \pm \mathrm{SD}, N=10)$ of soluble label was found as $\mathrm{ACh}$. The remaining label was divided between choline and an unidentified substance(s). To carry out stimulation experiments, the axons of B15 and B16 were stimulated via an extracellular suction electrode on nerve N3. This simplified carrying out the
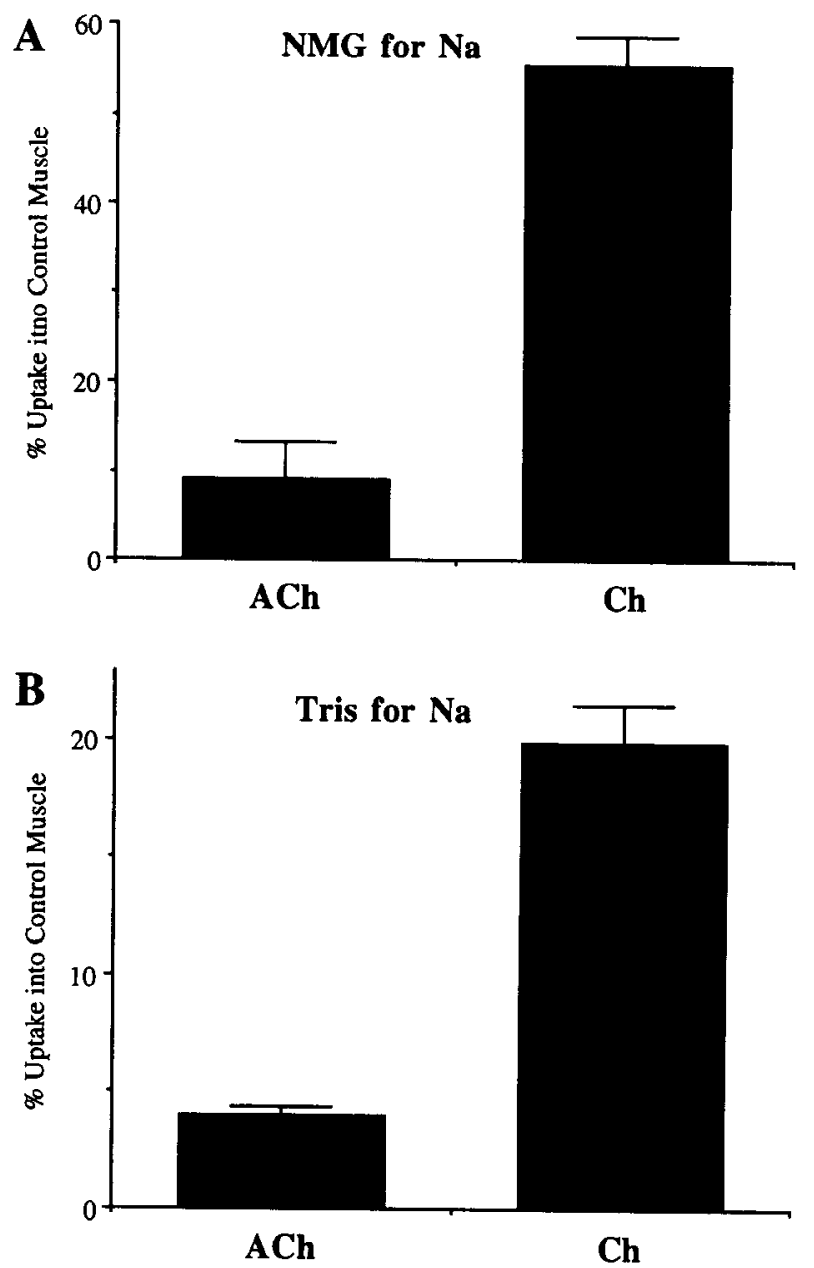

Figure 7. Inhibition of uptake of labeled $\mathrm{ACh}$ or $\mathrm{Ch}$ by reducing $[\mathrm{Na}]_{\text {. }}$. One of a pair of 15 muscles from an animal was incubated with $10 \mathrm{nM}$ ${ }^{3} \mathrm{H} \mathrm{ACh}$ or ${ }^{3} \mathrm{H} \mathrm{Ch}$ in normal $[\mathrm{Na}]_{o}(460 \mathrm{~mm})$, while the other muscle was incubated with the label in reduced $[\mathrm{Na}]_{o}(5 \mathrm{~mm}) . A$, Isotonicity maintained with $N$-methyl glucamine $(N M G)$. $B$, Isotonicity maintained with Tris. Incubation periods were 30 min. Values are mean $\pm \mathrm{SD}$ ( $n$ $=3$ ).

experiments, although other axons such as those of the serotonergic metacerebral cell would also be stimulated (Weiss et al., 1978). However, control experiments indicated that serotonin does not change either choline or ACh uptake (Phares and Lloyd, 1992). Nevertheless, intracellular stimulation of the MNs does not markedly simplify the situation as this is known to evoke release of peptide cotransmitters including some that are likely to have presynaptic actions on $\mathrm{ACh}$ release (Whim and Lloyd, 1989, 1990; Cropper et al., 1990a,b).

Paired unstimulated I5 muscles from one animal incubated in $50 \mathrm{nM}^{3} \mathrm{H}$-choline synthesized very similar amounts of labeled ACh (right : left ratio, $1.00 \pm 0.17, \pm \mathrm{SD}, n=5$ ). Stimulation of $\mathrm{N} 3$ increased labeled choline uptake and ACh synthesis markedly. When N3 to one muscle was stimulated, ${ }^{3} \mathrm{H}$-choline uptake doubled and labeled $\mathrm{ACh}$ increased $\sim$ five-fold. Both increases appeared to be linear up to $40 \mathrm{~min}$ (Fig. 8). Essentially, all (97.4 $\pm 5.0 \% ; \mathrm{SD}, n=5$ ) of the increased uptake of labeled choline was found to be synthesized into ACh (Fig. 9). There was no significant change in other labeled substances (stim/control, 1.04 \pm 0.07 ). When the same experiment was repeated using $50 \mathrm{~nm}$ ${ }^{3} \mathrm{H}-\mathrm{ACh}$, stimulation did not change total uptake or the ratio 

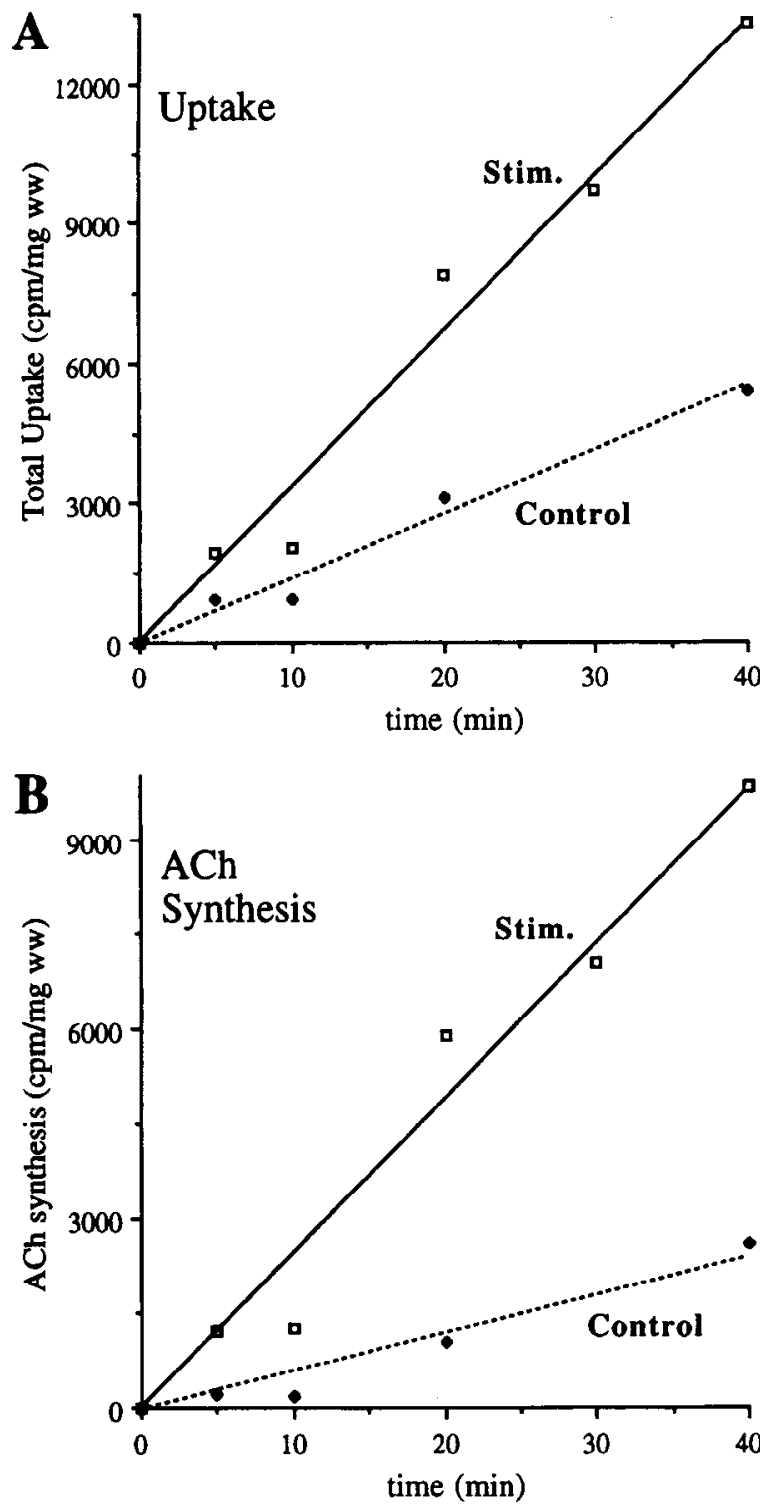

Figure 8. A, Stimulation of nerve $\mathrm{N} 3$ (which contains the axons of the MNs which innervate I5) increased the rate of uptake of $50 \mathrm{nM}^{3} \mathrm{H}-\mathrm{Ch}$ which was linear for at least $40 \mathrm{~min}$. Two muscles from the same animal were incubated in a single bath with ${ }^{3} \mathrm{H} \mathrm{Ch}$. A suction electrode was used to stimulate $\mathrm{N} 3$ to one of the muscles at $25 \mathrm{~Hz}$ for $4 \mathrm{sec}$ with 6 sec interburst intervals. $B$. Stimulation of nerve $\mathrm{N} 3$ increased the rate of labeled ACh synthesis from ${ }^{3} \mathrm{H} \mathrm{Ch}$ which was linear for at least 40 min. After incubation and washing, muscle extracts were run on HPLC to determine the fate of labeled $\mathrm{Ch}$ (see Fig. 9)

of labeled ACh found in the muscle (stim/control, $1.04 \pm 0.31$ for uptake, $1.04 \pm 0.07$ for ${ }^{3} \mathrm{H}-\mathrm{ACh}$ in muscle, $\pm \mathrm{SD}, n=6$ ). Thus, the high-affinity uptake of choline but not ACh was increased by stimulation. However, it should be noted that even when increased by stimulation, choline uptake was still half the velocity of $\mathrm{ACh}$ uptake.

\section{Evidence that the stimulation-dependent increase in choline uptake is localized to $M N$ axonal fibers}

The finding that all of the stimulation-dependent increase in choline uptake is synthesized into ACh suggests that this uptake occurs into a region with high CAT activity. The most likely identity for this region is the axonal fibers of the MNs. Two
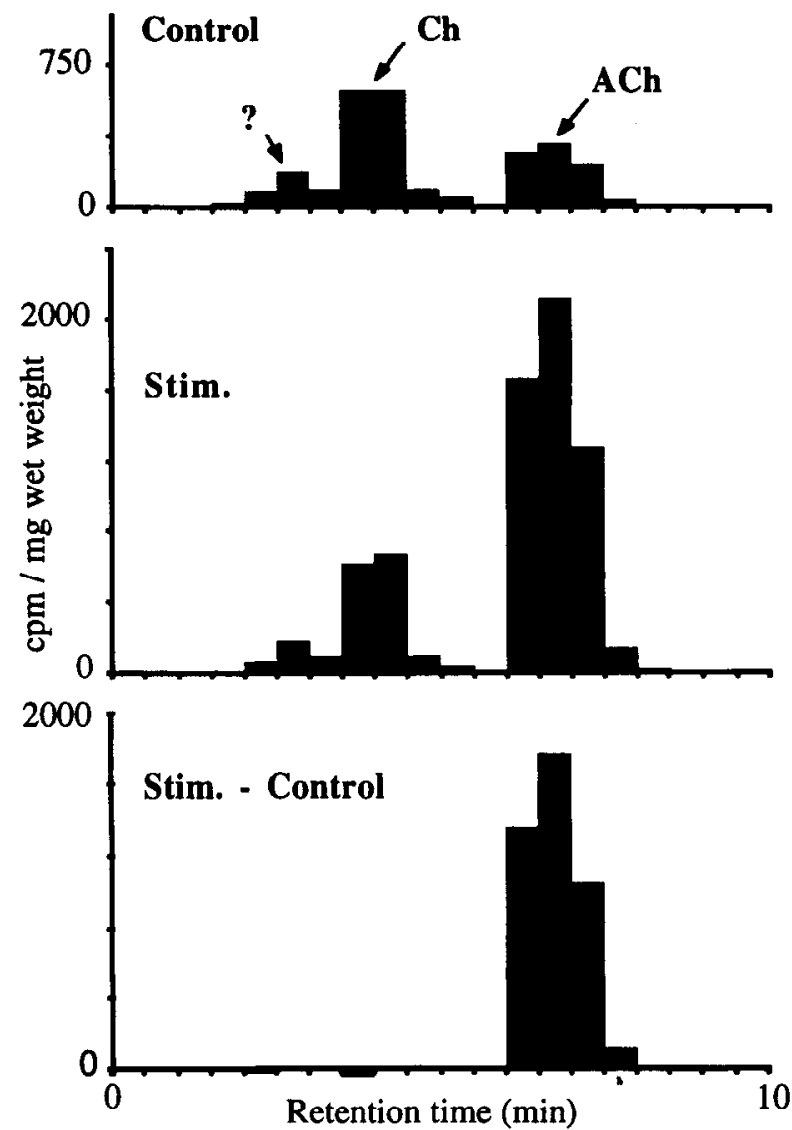

Figure 9. Stimulation of $\mathrm{N} 3$ increased total ${ }^{3} \mathrm{H}$-choline uptake and labeled ACh synthesis in 15 muscles. Paired muscles from one animal were incubated in $50 \mathrm{~nm}{ }^{3} \mathrm{H}-\mathrm{Ch}$ and $\mathrm{N} 3$ to one muscle stimulated via a suction electrode ( $4 \mathrm{sec}, 25 \mathrm{~Hz}$ burst with $6 \mathrm{sec}$ intervals for $30 \mathrm{~min}$ ). Muscles were then washed, extracted, and run on HPLC. Control is the profile from the unstimulated muscle. Stim. is the profile of the stimulated muscle. Stim. - Control is the difference between the two muscles. Note that all the additional labeled $\mathrm{Ch}$ taken up by the stimulated muscles was synthesized into ACh.

additional lines of evidence support this hypothesis. First, the stimulation-dependent increase in choline uptake has a very low capacity, as would be expected if the uptake was into a very small portion of 15 neuromuscular preparation. The stimulation-dependent increase in choline uptake is concentration dependent, with the effect essentially disappearing at concentrations of choline at or above $10 \mu \mathrm{M}$ (Fig. 10A). Subtracting uptake into stimulated muscles from uptake into the paired resting muscles revealed a stimulation-dependent high-affinity/low-capacity uptake system for choline, which saturated at $\sim 3 \mu \mathrm{M}$ and had an apparent $K_{\mathrm{m}}$ below $1 \mu_{\mathrm{M}}$ (Fig. $10 B$ ).

Second, the stimulation-evoked increase in ${ }^{3} \mathrm{H}$-choline uptake or synthesis of labeled $\mathrm{ACh}$ is not affected by blocking EJPs with the cholinergic antagonist hexamethonium. Paired muscles were both stimulated as described above in the presence of ${ }^{3} \mathrm{H}$ choline, but one muscle was incubated in sufficient hexamethonium $(0.5 \mathrm{mM})$ to substantially block EJPs and to abolish contractions (Whim and Lloyd, 1990). There are no differences between the muscle pairs in total uptake (control/hexamethonium, $0.97 \pm 0.14, \pm \mathrm{SD}, N=4)$ or in labeled ACh synthcsis (control/hexamethonium, $1.11 \pm 0.17$ ). Thus, the increases in choline uptake and $\mathrm{ACh}$ synthesis are independent of cholinergic depolarization of muscle fibers or muscle contractions. 

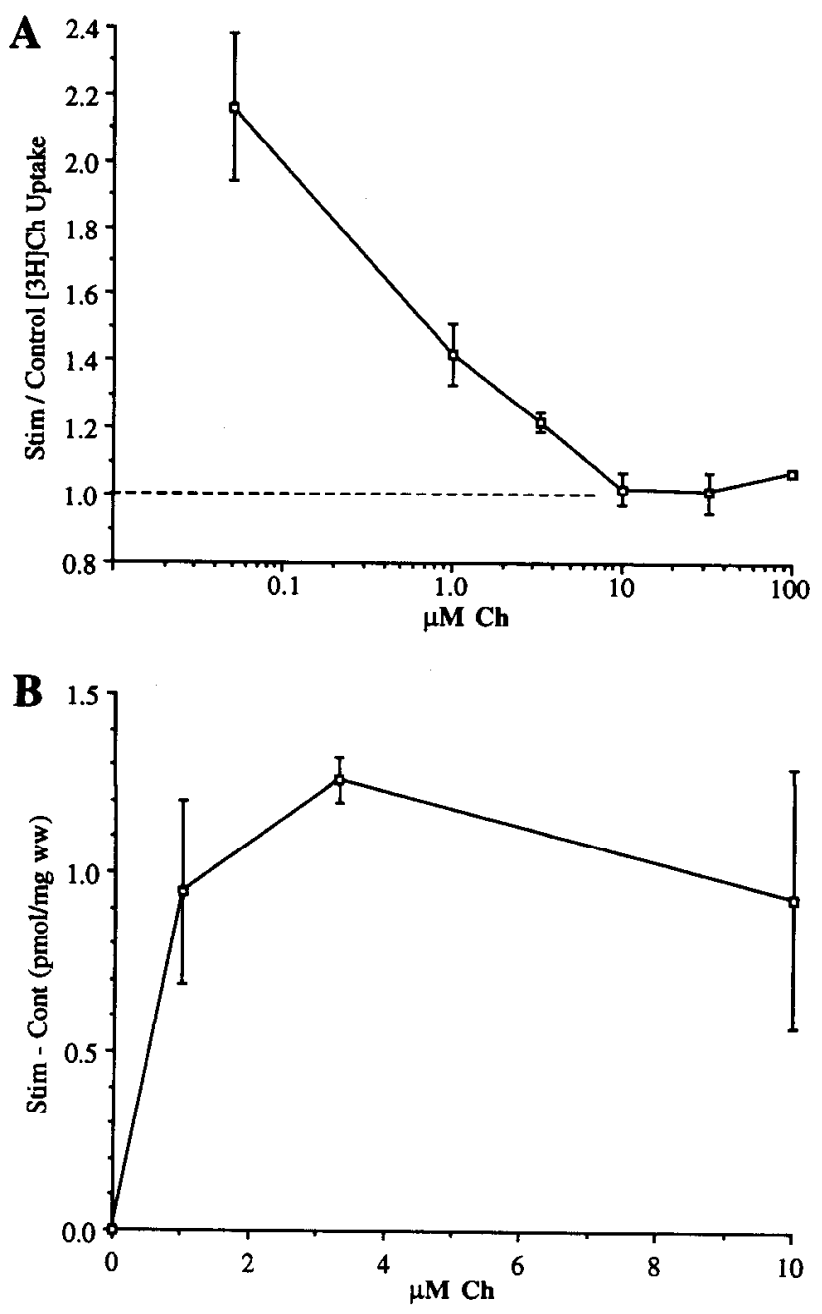

Figure 10. The effects of N3 stimulation on Ch uptake into I5 muscles decreased with increasing concentrations of Ch. Paired muscles from an animal were incubated with labeled $\mathrm{Ch}$ in the same dish and N3 to one muscle stimulated via a suction electrode $(4 \mathrm{sec}, 25 \mathrm{~Hz}$. bursts with $6 \mathrm{sec}$ intervals for $30 \mathrm{~min}$ ). A, Unlabeled $\mathrm{Ch}$ was added to $10 \mathrm{nM}{ }^{3} \mathrm{H}$ $\mathrm{Ch}$ to produce the indicated concentrations. Incubation periods were 30 min. Values are mean $\pm \mathrm{SD}(n=3)$. $B$, Subtracting uptake of $\mathrm{Ch}$ into the stimulated muscle from the uptake into the control muscle for each pair of muscles incubated with the same concentrations of $\mathrm{Ch}$ yields a saturating curve. Values are mean $\pm \mathrm{SD}(n=3)$. Note that the difference in uptake is very small compared to uptake values presented in Figure 5.

Again, this suggests that the most likely location for the increased uptake was into presynaptic axonal fibers of the MNs.

\section{Comparison of the rates of uptake and hydrolysis of $\mathrm{ACh}$}

In the I5 neuromuscular preparation, two mechanisms are present that are capable of reducing extracellular ACh concentrations, uptake, and hydrolysis. Since we had no way of blocking uptake completely, we reasoned that one way of comparing rates of $\mathrm{ACh}$ uptake to $\mathrm{AChE}$ activity would be to compare the fate of $10 \mu \mathrm{M}{ }^{3} \mathrm{H}-\mathrm{ACh}$ incubated with I5 muscle segments in the presence and absence of $100 \mu \mathrm{M}$ eserine. The assumption is that the eserine would completely block AChE activity but might not effect uptake (see below). It was neccssary to keep the ratio of the muscle volume to bath volume low (muscle : bath of 1:10) in order to be able to measure hydrolysis of labeled $\mathrm{ACh}$ in the bath. However, with this low ratio, the concentration of $\mathrm{ACh}$
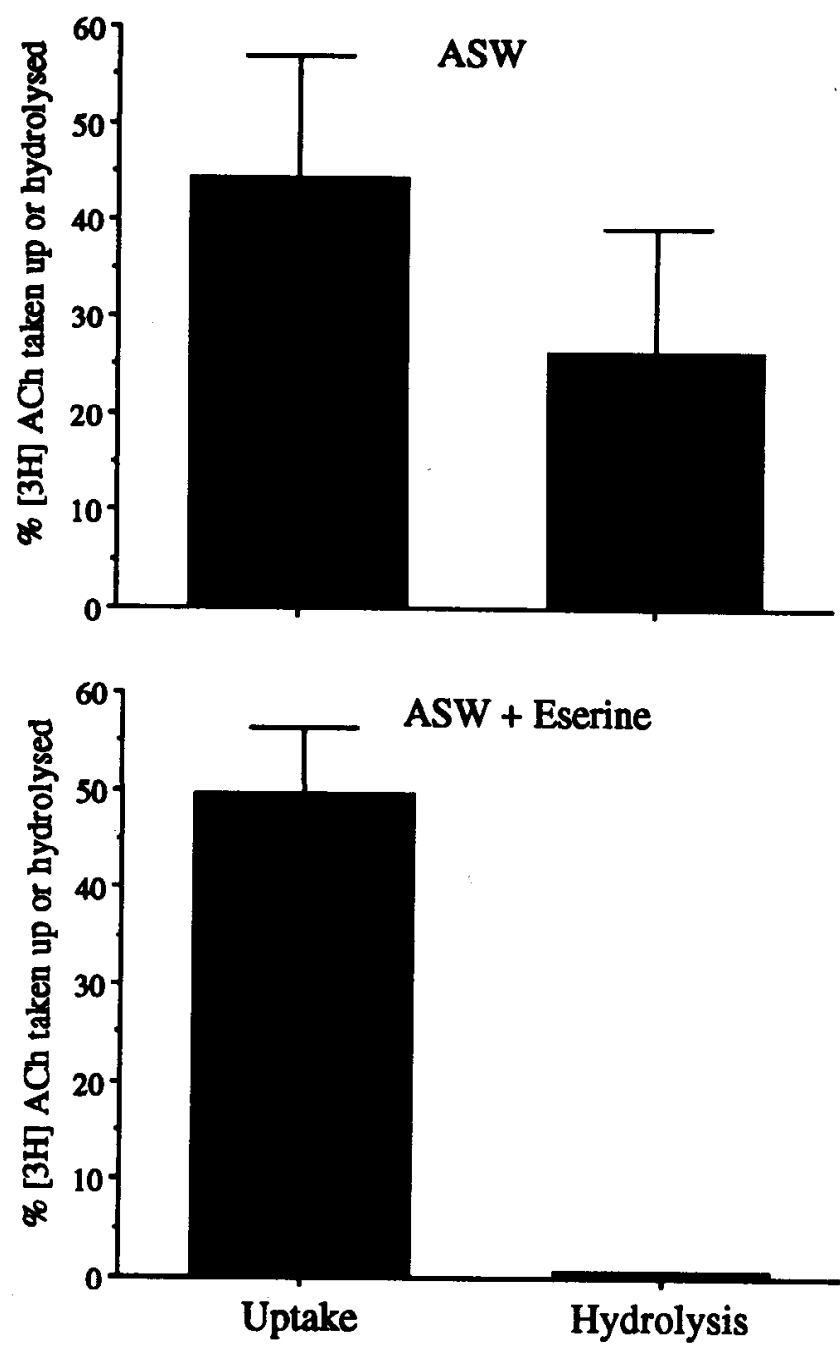

Figure 11. Comparison of uptake and hydrolysis of exogenous ${ }^{3} \mathrm{H}$ ACh incubated with I5 muscle segments. Muscle segments were incubated with $10 \mu \mathrm{M}{ }^{3} \mathrm{H}-\mathrm{ACh}$ in a ratio of $1 \mathrm{mg}$ wet weight: $10 \mu \mathrm{l}$ bath volume for 20 min either in nASW (top) or in nASW containing 100 $\mu \mathrm{M}$ eserine (bottom). At the end of the incubation period, the muscle segments were removed from the bath, washed, extracted and run on HPLC to measure labeled ACh and Ch. The bath was also extracted and run on HPLC. Values are mean $\pm \operatorname{SD}(n=3)$.

in the bath will be reduced by uptake. Preliminary experiments suggested that $\mathrm{ACh}$ hydrolysis was relatively slow and that 20 min was the optimal incubation period to measure hydrolysis without a large reduction in the concentration of $\mathrm{ACh}$ in the bath. Even at $20 \mathrm{~min}$, the $\mathrm{ACh}$ concentration was reduced to $4.8 \pm 0.4 \mu \mathrm{M}( \pm \mathrm{SD}, N=3)$ in $\mathrm{nASW}$ and to $6.1 \pm 0.4 \mu \mathrm{M}$ in nASW plus eserine. In nASW, more ACh was taken up than was hydrolyzed (Fig. 11). The presence of eserine blocked measurable hydrolysis of ACh $(<1 \%)$ but, as predicted, had no significant effect on uptake (Fig. 11). Thus, even in nASW, the uptake of $\mathrm{ACh}$ is more rapid than its hydrolysis by AChE. However, in the animal most of the AChE activity in muscle is likely to be due to activity found in the blood. The half-life of ${ }^{3} \mathrm{H}$-ACh in blood is $0.38 \pm 0.07 \mathrm{~min}(N=3$; blood diluted $1: 10$ in $\mathrm{nASW}$, the half-life would be considerably shorter in undiluted blood) and this activity was completely blocked by $100 \mu \mathrm{M}$ eserine. However, $\mathrm{AChE}$ in blood is particulate and it 
A
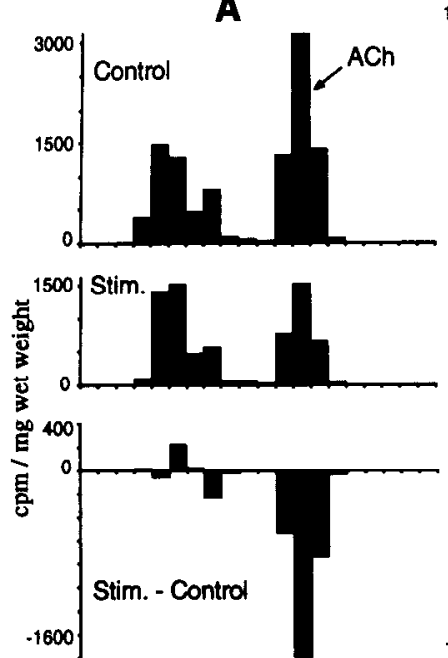

B

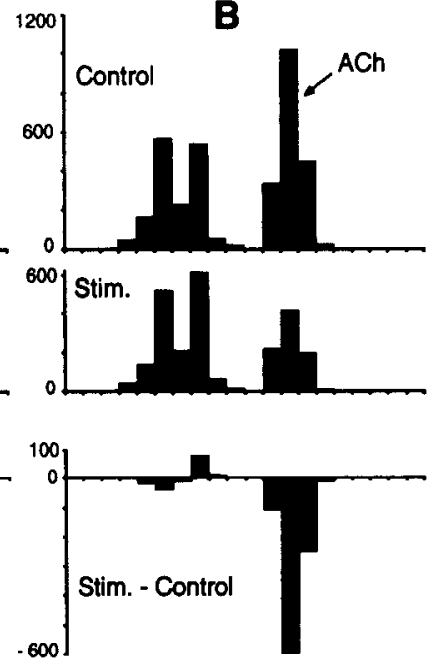

Figure 12. Stimulation selectively depletes labeled $\mathrm{ACh}$ from muscles preloaded by $\mathrm{N} 3$ stimulation in ${ }^{3} \mathrm{H}$-Ch. Paired muscles were both stimulated as described in Figure 8. Control is the profile of a muscle that was stimulated in labeled $\mathrm{Ch}$ then rested (no further stimulation). Stim. is the profile of a muscle that was stimulated in labeled $\mathrm{Ch}$ and then stimulated a second time after the labeled $\mathrm{Ch}$ had been removed. Stim. - Control is the difference between the two profiles. $A$, Second stimulation ( $25 \mathrm{~Hz}, 4 \mathrm{sec}$ bursts with $6 \mathrm{sec}$ intervals for $60 \mathrm{~min}$ ) was carried out in nASW with no additions. $B$, Second stimulation (as above) was carried out in nASW containing $100 \mu \mathrm{M}$ each of unlabeled $\mathrm{Ch}$, eserine, and hexamethonium. With these additions, muscle contractions were largely blocked and $\mathrm{AChE}$ activity was completely inhibited. Note that under both conditions, stimulation predominantly depletes labeled $\mathrm{ACh}$.

is not clear what role it would play in hydrolyzing $\mathrm{ACh}$ in the synaptic cleft (see Discussion).

Since eserine effectively blocked AChE activity in this preparation, we wished to determine what effects it would have on $\mathrm{MN}$-evoked contractions. In neuromuscular preparations washed extensively with nASW, B15 was stimulated via intracellular electrodes to fire bursts ( $1 \mathrm{sec}, 20 \mathrm{~Hz}$ bursts at $50 \mathrm{sec}$ intervals) which evoke contractions that are an extremely sensitive measure of neuromuscular depolarization in the 15 muscle (Cohen et al., 1978). At $100 \mu \mathrm{M}$, eserine actually caused a decline in the contraction amplitude (to $65 \pm 10 \%$ of control, \pm SEM, $n=3$ ) presumably due to some action on some aspect of neuromuscular transmission other than AChE. A lower concentration of eserine $(30 \mu \mathrm{M})$ did cause a moderate increase in contraction amplitude (to $112 \pm 3 \%$ of control, $n=3$ ). Unfortunately, all types of AChE inhibitors have been found to interact with cholinergic receptors in Aplysia (Fossier et al., 1983, 1984, 1986). Thus, eserine had only moderate effects on evoked contractions, suggesting that AChE activity does not play a large role in inactivating released $\mathrm{ACh}$ in the immediate region of the postjunctional cholinergic receptors.

\section{$A C h$ is the predominant labeled substance released in a stimulation-dependent marner}

When both neuromuscular preparations from an animal were loaded by nerve stimulation in labeled choline, they made much more labeled ACh than resting preparations and the amounts in each muscle were very similar (right : left ratio, $0.95 \pm 0.03$, $N=3$ ). Other labeled substances were also similar. Thus, if both neuromuscular preparations from an animal were loaded under identical conditions, washed, and then N3 to one muscle stim-

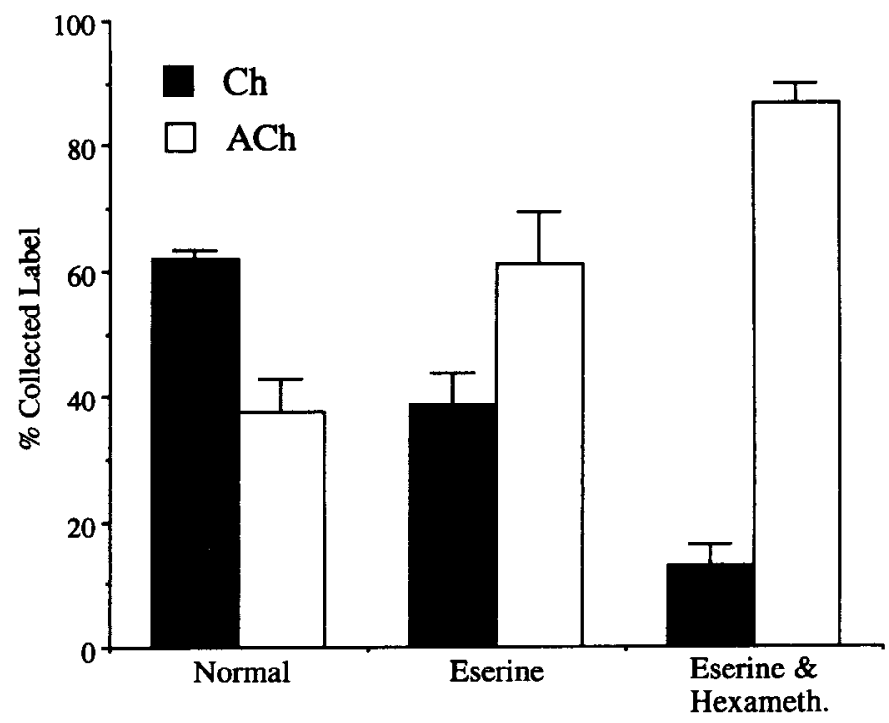

Figure 13. Composition of the increased label collected during stimulation of $\mathrm{N} 3(25 \mathrm{~Hz}$ for $4 \mathrm{sec}$ with $6 \mathrm{sec}$ intervals). In all cases, the increased label collected during stimulation was nearly all $\mathrm{ACh}$ and $\mathrm{Ch}$, but the ratio between the two was modified by adding eserine $(100 \mu \mathrm{M})$ to the nASW, or by adding eserine and hexamethonium $(500 \mu \mathrm{M})$ to the nASW. Composition of the collected labeled material was determined by HPLC. Values are mean $\pm \mathrm{SD}$ ( $n=4$ preparations).

ulated, released substances should be depleted from the stimulated side. Figure 12 shows examples of experiments done using this paradigm. The results of these experiments indicate that $\mathrm{ACh}$ is the major labeled substance depleted in a stimulation-dependent manner.

The nature of the labeled substances collected from neuromuscular preparations was also directly measured. I5 preparations were loaded by stimulation of $\mathrm{N} 3$ in the presence of labeled choline, then washed for 30 min and mounted in a collection apparatus perfused with $\mathrm{nASW}$. In resting neuromuscular preparations, the collected label was mostly ${ }^{3} \mathrm{H}$-choline in nASW alone (85.9 $\pm 8.3 \%, \pm \mathrm{SD}, n=4$ for each), in nASW plus 100 $\mu \mathrm{M}$ eserine $(88.4 \pm 7.8 \%)$, and in nASW plus eserine and 500 $\mu_{M}$ hexamethonium $(90.3 \pm 2.6 \%)$. Since eserine had no effect on this composition, the material collected from resting muscles probably represents choline gradually washing from the muscle. Nerve stimulation ( $25 \mathrm{~Hz}$ in $4 \mathrm{sec}$ bursts) increased the amount of collected label $3.13 \pm 1.00( \pm \mathrm{SD}, n=12)$ fold with a good deal of variability between preparations even under the same conditions. The stimulation-dependent increase in collected label was composed predominantly of choline and $\mathrm{ACh}$, but the relative composition was dependent on the perfusate. In nASW, somewhat more choline than $\mathrm{ACh}$ was collected (Fig. 13). Inhibiting AChE activity with eserine increases the proportion of label collected as ACh, suggesting that in $\mathrm{nASW}$ some hydrolysis of released ACh was occurring (Fig. 13). However, even in the presence of eserine, stimulation increased the recovery of labeled choline. Collected label was nearly all ACh when the EJPs and contractions were also inhibited with hexamethonium (Fig. 13). This suggests that stimulation caused a small increase in labeled choline efflux from the muscles presumably in response to the EJPs or contractions. Still, even in nASW alone, the stimulationdependent increase in collected label represents predominantly ACh released from terminals, although some of it has been hydrolyzed to choline. Of course, we expect that the labeled 
ACh and choline collected from neuromuscular preparations will be reduced to some degree by the high-affinity uptake systems.

\section{Collection of labeled ACh and choline during intracellular stimulation of $B 15$ or $B 16$}

We were interested in directly determining how stimulationdependent recovery of label is regulated by the stimulation frequency in individual MNs. After I5 neuromuscular preparations were loaded by stimulation of $\mathrm{N} 3$ during incubation in ${ }^{3} \mathrm{H}$ choline, individual B15 or B16 somata were impaled with two electrodes to control their electrical activity. In these experiments, only the I5 ncuromuscular preparation was bathed in nASW while other muscles and the buccal ganglion were bathed in low- $\mathrm{Ca}^{2+} / \mathrm{high}-\mathrm{Mg}^{2+} \mathrm{ASW}$. Under these conditions, B16 was often spontaneously active, while $B 15$ was always silent. In the experiments involving B15 stimulation, B16 was first impaled with an electrode and mechanically lesioned. Each MN was fired at a series of frequencies in $4 \mathrm{sec}$ bursts with $3 \mathrm{sec}$ intervals for 60 sec. Perfusate was collected as described for the nerve stimulation experiments. The label collected during a stimulation period was subtracted from two control collection periods before and after stimulation. Because levels of collected label fell off gradually during the experiments, stimulation at each frequency was bracketed with, and normalized to release during $10 \mathrm{~Hz}$ stimulation periods. Similar results were obtained for B15 and B16 (Fig. 14). Stimulation-dependent increases in collected label could be monitored at frequencies as low as $7.5 \mathrm{~Hz}$ (a total of 270 spikes in a single neuron) and as the frequency was increased the collected label increased markedly. When corrected for total number of spikes, the label collected per spike increased about 10-fold between $7.5 \mathrm{~Hz}$ and $25 \mathrm{~Hz}$, the highest frequency used in this study. As discussed above, we expect that the label collected from neuromuscular preparations will be reduced to some degree by the high-affinity uptake systems.

\section{Discussion}

The survey of identified buccal MNs indicated that the majority of these neurons use $\mathrm{ACh}$ as a fast excitatory transmitter. However, several MNs are not cholinergic and use a fast excitatory transmitter that we believe is an excitatory amino acid and probably glutamate (Fox and Lloyd, 1993). This observation is reminiscent of previous studies. For example, gill muscles of Aplysia were found to be innervated by both cholinergic and noncholinergic MNs (Carew et al., 1974). In addition, crustacean MNs are primarily glutamatergic (Gerschenfeld, 1973), but some have been shown to be cholinergic (Marder, 1976). In the present study, several of the buccal cholinergic MNs were inhibitory or mixed inhibitory/excitatory, but all of the noncholinergic MNs were excitatory. An interesting observation is that in muscle fibers in which the cholinergic MNs produce either an inhibitory or mixed response, the purely excitatory MNs to those fibers were noncholinergic (Church and Lloyd, 1991; Church et al., 1993). These results fit well with a hypothesis that postsynaptic neurons express the same type(s) of cholinergic receptors at all synapses made onto them by cholinergic neurons (Segal and Koester, 1982). Thus, it is possible that in muscle fibers that express inhibitory cholinergic receptors, the excitatory transmitter must be something other than ACh.

We have shown that the I5 neuromuscular system expresses separate high-affinity uptake systems for ACh and choline. The high-affinity uptake system for $\mathrm{ACh}$ is inhibited much more
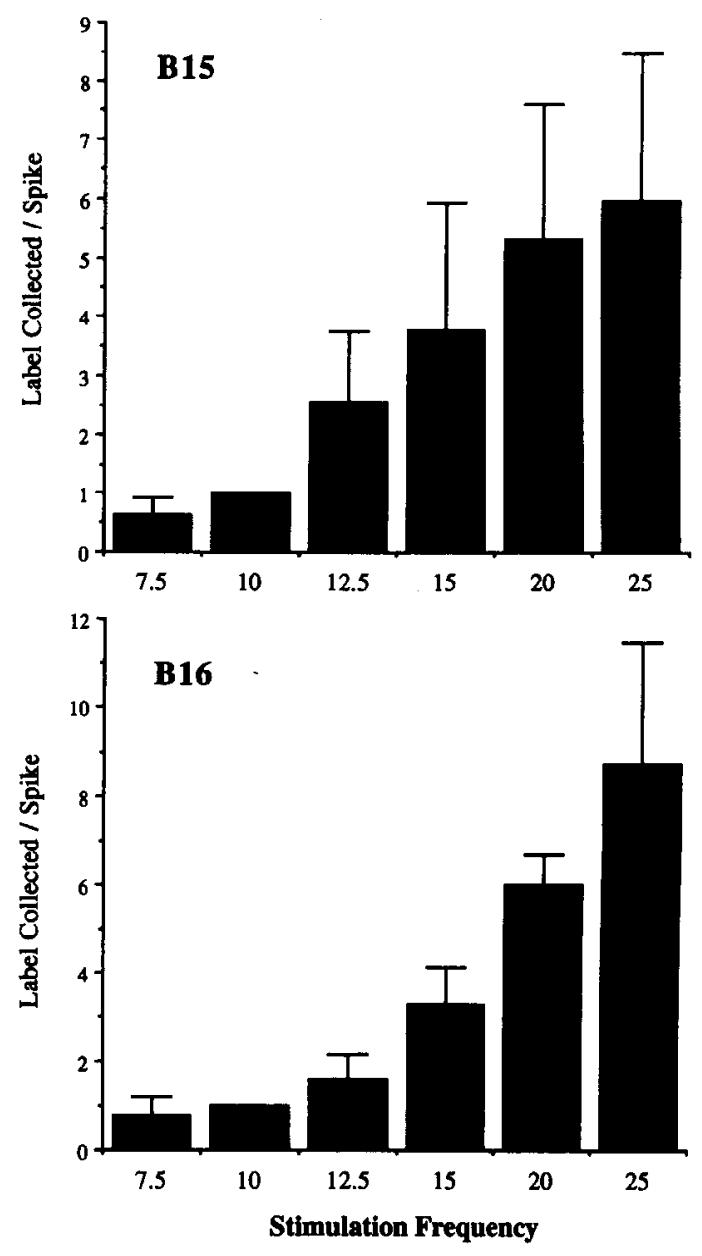

Figure 14. Stimulation-dependent recovery of label per spike increased with frequency for both B15 and B16. Most of this recovery represents release of ${ }^{3} \mathrm{H}-\mathrm{ACh}$. Muscles were stimulated in the presence of $50 \mathrm{~nm}{ }^{3} \mathrm{H}-\mathrm{Ch}$ to label ACh as described in Figure 8. After washing, either B15 or B16 was stimulated via intracellular electrodes to fire 4 $\mathrm{sec}$ bursts at the indicated frequencies with $3 \mathrm{sec}$ intervals for $60 \mathrm{sec}(9$ bursts). Release at each frequency was normalized to release from bracketing $10 \mathrm{~Hz}$ stimulation periods. Values are mean $\pm \mathrm{SD}(n \geq 4$ preparations).

effectively by high concentrations of ACh or by reducing external $\mathrm{Na}^{+}$concentrations than the high-affinity uptake system for choline. The velocity of uptake for $\mathrm{ACh}$ is about fourfold higher than that for choline in an unstimulated preparation. Even when choline uptake is increased by stimulation of motor axons, $\mathrm{ACh}$ uptake rates remain twice those for choline. The evidence suggests that the increase in uptake of labeled choline caused by stimulation occurs predominantly in the cholinergic axonal fibers in muscle. First, all of the increased uptake of choline is synthesized into $\mathrm{ACh}$. Thus, the choline is taken up into a region rich in CAT activity. This is likely to be the cholinergic axonal fibers, since most of the choline taken up into muscle fibers in the absence of stimulation is not metabolized to ACh. Second, this increased choline uptake and ACh synthesis caused by stimulation is unchanged when postsynaptic responses are inhibited by hexamethonium. Again, this makes it likely that the site of the stimulation-dependent changes are the presynaptic axonal fibers. It is pcrhaps surprising that this should be the case given that these terminals make up such a small proportion of the 
volume of this neuromuscular preparation. However, it may be that the very low concentrations of choline $(\leq 50 \mathrm{~nm})$ used in many of these studies ensured that almost all of the uptake is through a high-affinity system that is expressed preferentially in the presynaptic MN fibers (see also Eisenstadt and Schwartz, 1975; Eisenstadt et al., 1975). The finding that the rate of the high-affinity uptake of $\mathrm{ACh}$ is not changed by stimulation could be because ACh is taken up by muscles cells or glia, or the uptake is into $\mathrm{MN}$ fibers and it is simply regulated differently from the high-affinity uptake system for choline. Perhaps the choline uptake system is primarily responsible for maintaining homeostatic levels of ACh because choline is always readily available in substantial concentrations in the blood (Schwartz et al., 1975).

Taken together, our results suggest that the additional labeled choline and ACh collected from I5 neuromuscular preparations during stimulation is predominantly due to release of $\mathrm{ACh}$ from MN terminals and is therefore a reasonable reflection of this release. Thus, it should prove possible to determine factors that regulate conventional transmitter release in a preparation that has become a model system for the study of the release of peptide cotransmitters (Whim and Lloyd, 1989, 1990; Cropper et al., 1990a; Villim et al., 1991; Phares and Lloyd, 1992). In this regard, it is interesting to note that $\mathrm{ACh}$ release from terminals of B15 appears to increase smoothly with stimulation frequency. In contrast, there appears to be a discrete frequency threshold for the release of B15's cotransmitters (the SCPs) below which no release occurs (Whim and Lloyd, 1989, 1990). However, it should also be noted that the uptake of $\mathrm{ACh}$, and to a lesser degree that of choline produced by hydrolysis of $\mathrm{ACh}$, will always ensure that the collected label underrepresents the release of labeled ACh.

Several aspects of the results presented here differ significantly from those obtained previously from studies carried out in the abdominal ganglion. In one study, release experiments were carricd out on neurons injected with ${ }^{3} \mathrm{H}$-choline (Koike et al., 1974). Although the injected labeled choline was efficiently synthesized into $\mathrm{ACh}$, only labeled choline was recovered from the perfusate after intracellular stimulation suggesting rapid hydrolysis by $\mathrm{AChE}$. This hydrolysis was not prevented by a variety of AChE inhibitors. It is possible that the existence of the highaffinity uptake system for $\mathrm{ACh}$ we have described in the abdominal ganglion contributed to the inability to recover labeled $\mathrm{ACh}$. In the present experiments, nearly half of the label collected during stimulation was $\mathrm{ACh}$ in the complete absence of inhibitors of $\mathrm{AChE}$ or uptake. It is also possible that the different results may also reflect differences in the methods of loading the synapses with labeled ACh. In the study of the abdominal ganglion, labeled choline was injected into the cell body and an interval provided for synthesis of $\mathrm{ACh}$ and diffusion or transport to terminals. In our study, labeled choline was taken up during stimulation and the labeled $\mathrm{ACh}$ appears to be confined to the MN terminals. Presumably, this latter mode of loading is more physiological. A second major difference with the results of a previous study is the finding in the abdominal ganglion that nerve stimulation did not increase either choline uptake or $\mathrm{ACh}$ synthesis (Eisenstadt et al., 1975). This was interpreted as being a reflection of the large pools of ACh found in Aplysia neurons. We found that stimulation produced large increases in both choline uptake and ACh synthesis in the 15 neuromuscular preparation that were qualitatively similar to those observed for vertebrate neuromuscular preparations (Potter, 1970; Vaca and
Pilar, 1979). It is possible that stimulation of peripheral nerves to the $I 5$ muscle is much more effective at activating cholinergic terminals than stimulation of nerve roots leading back into the abdominal ganglion. An alternative explanation is that cholinergic metabolism in central and peripheral synapses in Aplysia differ significantly.

The quantitative relationship between hydrolysis of ACh by endogenous $\mathrm{AChE}$ and high-affinity uptake of ACh appears to differ significantly between the I5 neuromuscular system and vertebrate skeletal neuromuscular preparations. For example, in rat diaphragm, there is no measurable uptake of $\mathrm{ACh}$ in the absence of an AChE inhibitor, and even in the presence of an inhibitor, the rate of ACh uptake was half that observed for choline under identical conditions (using $10 \mu \mathrm{M}$ ACh or choline; Potter, 1970). In the Aplysia I5 system, there is measurable $\mathrm{AChE}$ activity, but the presence of an AChE inhibitor has little effect on ACh uptake. In addition, at concentrations of $10 \mu \mathrm{M}$, the rate of ACh uptake is about fourfold that of choline. It is possible that under normal physiological conditions, the $\mathrm{AChE}$ activity in blood is responsible for the rapid hydrolysis of released ACh. However, AChE activity in Aplysia blood is associated with particles that are retained by filters with a pore size of $200 \mathrm{~nm}$ (Giller and Schwartz, 1971 b; Bevelaqua et al., 1975). Since the synaptic cleft in 15 muscle is about $20 \mathrm{~nm}$ across (Kupfermann et al., 1982; Cropper et al., 1987a), it is not clear what role the blood AChE would play in the rapid hydrolysis of released ACh. It appears likely that it primarily hydrolyzes $\mathrm{ACh}$, which has already diffused from the synapse. Neural elements in the $\mathbf{5}$ muscle do stain with a histochemical procedure for cholinesterase, but staining was not confined to varicosities and even large nonvaricose axons stained. This suggests that the small amount of AChE activity endogenous to this neuromuscular preparation may not even be concentrated at synapses (Cohen et al., 1978). Thus, at these cholinergic neuromuscular synapses, efficient uptake of the unhydrolyzed transmitter may play a role in reducing the concentration of $\mathrm{ACh}$ in the synaptic cleft, as has been suggested for the biogenic amines and amino acid transmitters (Bruns et al., 1993; Mennerick and Zorumski, 1994).

Recordings from behaving animals indicate that both B15 and B16 can fire in sustained bursts with a duration of a few seconds and brief interburst intervals similar to the pattern used in this study (Cropper et al., 1990c). Our direct measurements of collected label suggest that the two motor neurons show similar frequency-dependent increases in release per spike $(\sim 10-$ fold range for the frequencies tested). Cohen et al. (1978) concluded that the EJPs from B1 5 showed much greater facilitation than those from B16 by comparing the size of EJPs generated by two action potentials fired intracellularly with varying intervals. Differences in stimulation parameters may underlie this apparent contradiction, since our stimulation paradigm used a train of long duration bursts.

In conclusion, we have shown that ACh is a major conventional excitatory transmitter of buccal neuromuscular synapses. We also found that the 15 neuromuscular system is amenable to the investigation of the release of a conventional transmitter from the terminals of individual identified MNs. We now intend to compare the regulation of peptide cotransmitters and $\mathrm{ACh}$ release from the terminals of the same neurons. We have also raised the possibility that the uptake of ACh may play a role in transmitter inactivation at these synapses similar to what has been observed elsewhere for noncholinergic transmitters. 


\section{References}

Amara SG, Kuhar MJ (1993) Neurotransmitter transporters: recent progress. Annu Rev Neurosci 16:73-93.

Bartfai T, Iverfeldt K, Fisone G, Serfozo P (1988) Regulation of the release of coexisting transmitters. Annu Rev Pharmacol Toxicol 28: 285-310.

Bevelaqua FA, Kim KS, Kumarasiri MH, Schwartz JH (1975) Isolation and characterization of acetylcholinesterase and other particulate proteins in the hemolymph of Aplysia californica. J Biol Chem 250:731-738.

Bruns D, Engert F, Lux H-D (1993) A fast activating presynptic reuptake current during serotonergic transmission in identified neurons of Hirudo. Neuron 10:559-572.

Carew TJ, Pinsker H, Runinson K, Kandel ER (1974) Physiological and biochemical properties of neuromuscular transmission between identified motoneurons and gill muscle in Aplysia. J Neurophysiol 37:1020-1040.

Church PJ, Lloyd PE (1991) Expression of diverse neuropeptide cotransmitters by identified motor neurons in Aplysia. J Neurosci 11: 618-625.

Church PJ, Whim MD, Lloyd PE (1993) Modulation of neuromuscular transmission by conventional and peptide transmitters released from excitatory and inhibitory motor neurons in Aplysia. J Neurosci $13: 2790-2800$.

Coggeshall RE (1967) A light and electron microscope study of the abdominal ganglion of Aplysia californica. J Neurophysiol 30:12631287.

Cohen JL, Weiss KR, Kupfermann I (1978) Motor control of buccal muscles in Aplysia. J Neurophysiol 41:157-180.

Cropper EC, Lloyd PE, Reed W, Tenenbaum R, Kupfermann I, Weiss KR (1987a) Multiple neuropeptides in cholinergic motor neurons of Aplysia: evidence for modulation intrinsic to the motor circuit. Proc Natl Acad Sci USA 84:3486-3490.

Cropper EC, Tenenbaum R, Gawinowicz Kolks MA, Kupfermann I, Weiss KR (1987b) Myomodulin: a bioactive neuropeptide present in an identified cholinergic buccal motor neuron of Aplysia. Proc Natl Acad Sci USA 84:5483-5486.

Cropper EC, Miller MW, Tenenbaum R, Gawinowicz Kolks MA, Kupfermann I, Weiss KR (1988) Structure and action of buccalin: a modulatory neuropeptide localized to an identified small cardioactive peptide-containing cholinergic motor neuron of Aplysia californica. Proc Natl Acad Sci USA 85:6177-6181.

Cropper EC, Price D, Tenenbaum R, Kupfermann I, Weiss KR (1990a) Release of peptide cotransmitters from cholinergic neuron under physiological conditions. Proc Natl Acad Sci USA 87:933-937.

Cropper EC, Miller MW, Villim FS, Tenenbaum R, Kupfermann I, Weiss KR (1990b) Buccalin is present in the cholinergic motor neuron B16 of Aplysia and it depresses accessory radula closer muscle contractions evoked by stimulation of B16. Brain Res 512:175-179.

Cropper EC, Kupfermann I, Weiss KR (1990c) Differential firing patterns of the peptide-containing cholinergic motor neurons B15 and B16 during feeding behavior in Aplysia. Brain Res 522:176-179.

Eisenstadt ML, Schwartz JH (1975) Metabolism of acetylcholine in the nervous system of Aplysia californica. III. Studies of an identified cholinergic neuron. J Gen Physiol 65:293-313.

Eisenstadt ML, Goldman JE, Kandel ER, Koike H, Koester J, Schwartz JH (1973) Intrasomatic injections of radioactive precusrsors for studying transmitter synthesis in identified neurons of Aplysia californica. Proc Natl Acad Sci USA 70:3371-3375.

Eisenstadt ML, Treistman SN, Schwartz JH (1975) Metabolism of acetylcholine in the nervous system of Aplysia californica. II. Regional localization and characterization of choline uptake. J Gen Physiol 65: 275-291.

Fossier P, Baux G, Tauc L (1983) Direct and indirect effects of organophosphorus acetylcholinesterase inhibitor and of an oxime on a neuro-neuronal synapse. Pfluegers Arch 396:15-22.

Fossier P, Baux G, Tauc I, (1984) Postsynaptic acetylcholine receptor efficacy is similarly increased by detergents and acetylcholinesterase at an Aplysia synapse. Brain Res 308:369-372.

Fossicr P, Baux G, Tauc L (1986) Fasciculin II, a protein inhibitor of acetylcholinesterase, tested on a central synapse in Aplysia. Cell Mol Neurobiol 6:221-225.

Fox LE, Lloyd PE (1993) Evidence that L-glutamate is the excitatory transmitter to buccal muscle I3 in Aplysia. Soc Neurosci Abstr 19: 490.
Gardner D, Kandel ER (1977) Physiological and kinetic properties of cholinergic receptors activated by multiaction interneurons in buccal ganglia of Aplysia. J Neurophysiol 40:333-348.

Gerschenfeld HM (1973) Chemical transmission in invertebrate central nervous systems and neuromuscular junctions. Physiol Rev 53: 1-119.

Giller E, Schwartz JH (1971a) Choline acetyltransferase in identified neurons of abdominal ganglion of Aplysia californica. J Neurophysiol 34:93-107.

Giller E, Schwartz JH (1971b) Acetylcholinesterase in identified neurons of abdominal ganglion of Aplysia californica. J Neurophysiol 34: $108-115$.

Howells HH (1942) The structure and function of the alimentary canal of Aplysia punctata. Q J Microsc 83:357-397.

Jordan R, Cohen KP, Kirk MD (1993) Control of intrinsic buccal muscles by motoneurons B11, B15, and B16 in Aplysia californica. J Exp Zool 265:496-506.

Koike H, Kandel ER, Schwartz JH (1974) Synaptic release of radioactivity after intrasomatic injection of choline $-{ }^{3} \mathrm{H}$ into an identified cholinergic neuron in the abdominal ganglion of Aplysia californica. J Neurophysiol 37:815-827.

Kupfermann I (1991) Functional studies of cotransmission. Physiol Rev 71:683-732.

Kupfermann I, Shkolnik L, Weiss KR (1982) Modulatory synaptic actions of neurotransmitters in circuits controlling feeding in Aplysia. In: Cytochemical methods in neuroanatomy. New York: A Liss.

Lloyd PE (1988) Fast axonal transport of modulatory neuropeptides from central ganglia to components of the feeding system in Aplysia. J Neurosci 8:3507-3514.

Lloyd PE, Kupfermann I, Weiss KR (1988) Central peptidergic neurons regulate gut motility in Aplysia. J Neurophysiol 59:1613-1626.

Lotshaw DP, Lloyd PE (1990) Peptidergic and serotonergic facilitation of a neuromuscular synapse in Aplysia. Brain Res 526:81-94.

Marder E (1976) Cholinergic motor neurones in the stomatogastric system of the lobster. J Physiol (Lond) 257:63-86.

McCaman RE, Weinreich D, Borys H (1973) Endogenous levels of acetylcholine and choline in individual neurons of Aplysia. J Neurochem 21:473-476.

Mennerick S, Zorumski CF (1994) Glial contributions to excitatory transmission in cultured hippocampal cells. Nature 368:59-62.

Ono JK, McCaman RE (1980) Identification of additional histaminergic neurons in Aplysia: improvement of single cell isolation techniques for in tandem physiological and chemical studies. Neuroscience 5:835-840.

Phares GA, Lloyd PE (1992) Modulation of ACh release from neuromuscular synapses in Aplysia. Soc Neurosci Abstr 18:469.

Potter LT (1970) Synthesis, storage and release of $\left[{ }^{14} \mathrm{C}\right]$ acetylcholine in isolated rat diaphragm muscles. J Physiol (Lond) 206:145-166.

Schwartz JH, Eisenstadt ML, Cedar H (1975) Metabolism of acetylcholine in the nervous system of Aplysia californica. I. Source of choline and its uptake by intact nervous tissue. J Gen Physiol 65: 255-273.

Segal MM, Koester J (1982) Convergent cholinergic neurons produce similar postsynaptic actions in Aplysia: implications for neural organization. J Neurophysiol 47:742-759.

Vaca K, Pilar G (1979) Mechanisms controlling choline transport and acetylcholine synthesis in motor nerve terminals during electrical stimulation. J Gen Physiol 73:605-628.

Villim FS, Price DA, Lesser W, Kupfermann I, Weiss KR (1991) Direct measurement of peptide co-transmitter release following intracellular stimulation of single identified motoneurons in Aplysia. Soc Neurosci Abstr 17:1305.

Weiss KR, Cohen J, Kupfermann I (1978) Modulatory control of buccal musculature by a serotonergic neuron (metacerebral cell) in Aplysia. J Neurophysiol 41:181-203.

Whim MD, Lloyd PE (1989) Frequency-dependent release of peptide cotransmitters from identified cholinergic motor neurons in Aplysia. Proc Natl Acad Sci USA 86:9034-9038.

Whim MD, Lloyd PE (1990) Neuropeptide cotransmitters released from an identified cholinergic motor neuron modulate neuromuscular efficacy in Aplysia. J Neurosci 10:3313-3322.

Whim MD, Church PJ, Lloyd PE (1993) Functional roles of peptide cotransmitters at neuromuscular synapses in Aplysia. Mol Neurobiol 7:335-347. 